NBER WORKING PAPER SERIES

\title{
MIGRATION AND HEDONIC VALUATION: THE CASE OF AIR QUALITY
}

\author{
Patrick Bayer \\ Nathaniel Keohane \\ Christopher Timmins \\ Working Paper 12106 \\ http://www.nber.org/papers/w12106 \\ NATIONAL BUREAU OF ECONOMIC RESEARCH \\ 1050 Massachusetts Avenue \\ Cambridge, MA 02138 \\ March 2006
}

We would like to thank Wayne Gray, Michael Greenstone, Brian Murray, Sharon Oster, Ray Palmquist, Kerry Smith, and seminar and conference participants at Brown, Harvard-MIT, Yale, Resources for the Future, the 2004 AERE Summer Workshop, and the 2005 Camp Resources for their helpful comments and insights. All remaining errors and omissions are our own. The views expressed herein are those of the author(s) and do not necessarily reflect the views of the National Bureau of Economic Research.

(C2006 by Patrick Bayer, Nathaniel Keohane, and Christopher Timmins. All rights reserved. Short sections of text, not to exceed two paragraphs, may be quoted without explicit permission provided that full credit, including $@$ notice, is given to the source. 
Migration and Hedonic Valuation: The Case of Air Quality

Patrick Bayer, Nathaniel Keohane, and Christopher Timmins

NBER Working Paper No. 12106

March 2006

JEL No. H5, Q2, Q5, R1

\begin{abstract}
Conventional hedonic techniques for estimating the value of local amenities rely on the assumption that households move freely among locations. We show that when moving is costly, the variation in housing prices and wages across locations may no longer reflect the value of differences in local amenities. We develop an alternative discrete-choice approach that models the household location decision directly, and we apply it to the case of air quality in U.S. metro areas in 1990 and 2000. Because air pollution is likely to be correlated with unobservable local characteristics such as economic activity, we instrument for air quality using the contribution of distant sources to local pollution - excluding emissions from local sources, which are most likely to be correlated with local conditions. Our model yields an estimated elasticity of willingness to pay with respect to air quality of 0.34 to 0.42 . These estimates imply that the median household would pay $\$ 149$ to $\$ 185$ (in constant 1982-1984 dollars) for a one-unit reduction in average ambient concentrations of particulate matter. These estimates are three times greater than the marginal willingness to pay estimated by a conventional hedonic model using the same data. Our results are robust to a range of covariates, instrumenting strategies, and functional form assumptions. The findings also confirm the importance of instrumenting for local air pollution.
\end{abstract}

\author{
Patrick Bayer \\ Department of Economics \\ Yale University \\ Box 208264 \\ New Haven, CT 06520-8264 \\ and NBER \\ patrick.bayer@yale.edu
}




\section{Introduction}

Since Rosen's (1974) seminal paper, economists have used hedonic techniques to estimate the value of a wide range of amenities, including clean air, school quality, and lower crime rates. The great attraction of the approach is that it uses observed behavior in housing and labor markets to infer the value of non-market goods. On the standard assumption that individuals choose the residential locations that maximize their utility, marginal rates of substitution between local amenities and other goods will equal the price ratio. Hence the marginal willingness to pay for those amenities can be measured by their implicit prices, as reflected in housing prices and wages. The broad avail of this approach, along with considerable practical interest in the estimates it provides, explains the continuing interest among economists in the theory and identification of hedonic models. ${ }^{1}$

This paper addresses a crucial but often overlooked assumption in hedonic models, and shows how that assumption may lead to biased estimates of willingness to pay for local amenities. Hedonic models typically assume that people can move freely among locations when they buy homes and choose jobs. If so, wages and rents must adjust to reflect the implicit prices of local amenities; hence, willingness to pay can be inferred from variation in housing prices and income. The key assumption of perfect mobility, however, ignores an important feature of the real world: migration is costly. Moving to a new city entails not only out-of-pocket costs, but (much more important) psychic costs of leaving behind one's family and cultural roots. Data on residential choices suggests that such costs are significant. Table 1 relates birth location to residential location: it shows that great majority of U.S. household heads reside in the region of their birth. A similar pattern holds at the state level. This strong revealed preference for staying close to home belies the assumption that residential choices reflect a simple tradeoff between local attributes and prevailing rents and wages. If migration costs enter into residential location decisions, they should be considered by analysts measuring the value of local amenities.

How will migration costs affect estimates of willingness to pay? Consider an exogenous improvement in air quality in a particular city. In response, we would expect housing prices to rise and wages to fall until a new equilibrium is reached. If migration is costless, these changes will fully reflect the value of the cleaner air. But if migration is costly, the change in housing prices and wages must be smaller: the benefit someone gets from moving to the city must now compensate her not only for the higher rents and lower income, but also for the cost of moving. To see the intuition, consider someone born in Detroit who would willingly pay $\$ 100$ for the gain in air quality that she would get from moving to an otherwise identical neighborhood in Tucson. If the disutility of moving to the new city is $\$ 40$, she 
will move only if the difference in housing prices (net of income) is less than $\$ 60$. Hence the change in housing prices and wages that accompanies a change in air quality will understate willingness to pay for clean air. Notice also that the extent of the understatement depends on the size of migration costs relative to the benefits from the amenity - a point to which we will return below.

Beyond the theoretical questions of identification and estimation, numerical estimates of the value of local public goods are of great practical interest. Again consider the example of air quality, whose protection motivates a range of government policies that impose substantial costs on firms and consumers. A comprehensive survey of cross-sectional hedonic property value studies found wide dispersion in estimated willingness to pay, with many instances of negligible or even negative estimates (Smith and Huang 1995). If those low estimates are reliable, the costs of stringent air pollution regulation may outweigh the benefits. On the other hand, evidence that such estimates understate the value of clean air would bolster the case for government policy.

In this paper, we show how migration costs can be incorporated into a hedonic analysis. We start by incorporating migration into the canonical wage-hedonic model proposed by Roback (1982). If moving is costly, then the sum of the derivatives of housing prices and wages with respect to the amenity - the standard hedonic measure of marginal willingness to pay - will no longer equal the implicit price of the amenity. The more costly is migration relative to the marginal benefits of an improvement in the amenity, the greater will be the bias from ignoring migration costs in the analysis.

To allow for costly mobility, we employ a different empirical strategy. The starting point for our analysis is the household location decision, rather than the first order condition implied by a traditional hedonic model. This approach allows us to incorporate migration costs (as the implicit disutility of moving various distances from one's birth state) directly into the household optimization problem.

We apply our method to the case of air quality - specifically, ambient concentrations of particular matter ("PM10") in metropolitan areas throughout the U.S., for the years 1990 and 2000. We study air pollution in general, and PM10 in particular, for a number of reasons. First, an estimate of the economic value of improvements in air quality is of central importance to the U.S. Environmental Protection Agency in the regulation of air pollution under the Clean Air Act and its subsequent amendments. Second, air quality improved significantly over the decade studied, providing useful panel variation. Third, migration costs are likely to be large relative to the potential gains of changing locations for the sake of air quality; hence ignoring such costs is likely to produce substantial bias in estimates of WTP for

\footnotetext{
${ }^{1}$ The study of the theory and identification of hedonic markets in competitive settings dates back to Rosen (1974). The topic has recently seen a resurgence with methodological papers by Ekeland, Heckman and Nesheim (2004), Heckman, Matzkin, and Nesheim (2005), and Bajari and Benkard (2001).
} 
air quality. ${ }^{2}$ Fourth, a long literature, dating back to Ridker and Henning (1967) and Harrison and Rubinfeld (1978), has used hedonic methods to value air quality (see Smith and Huang (1995) for a metaanalysis). Finally, particulate matter is a natural choice of pollutant: it is the standard measure of air pollution used in the literature, and an increasing body of evidence suggests that it is by far the most important local air pollutant in terms of health effects.

Our empirical analysis proceeds in two stages. First, we use a discrete-choice model to infer the utility associated with living in various metropolitan areas. We then regress these metro-area utilities on air pollution concentrations in order to recover the willingness to pay for air quality. This second stage is analogous to the traditional hedonic approach, which regresses housing prices on air pollution. An identification problem thus arises that is endemic to hedonic analyses. As Chay and Greenstone (2005) point out, local air quality is likely to be correlated with unobserved local economic factors that also affect housing prices. If so, naïve estimates of willingness to pay will be biased downward - helping to explain the low estimates reported in the existing literature.

We employ a novel instrumental variables approach to deal with this endogeneity problem. The intuition behind our approach is simple. Although local emissions (correlated with local economic activity) are the major determinant of local air quality, pollution also wafts in from distant sources. The tall stacks of electric power plants spew particulate matter and other pollutants high into the atmosphere, where they travel great distances before affecting ground-level air quality. Distant emissions, however, are likely to be uncorrelated with local economic activity - a conjecture that is confirmed by the data. Hence pollution from distant sources provides a natural instrument for local air pollution. We compute this instrument using a detailed source-receptor matrix, developed for the U.S. EPA, that relates emissions from nearly 6,000 sources to particulate matter concentrations in each county in the U.S.

Our results demonstrate the importance of accounting for endogeneity and incorporating mobility costs. As a preliminary step, we estimate a traditional wage-hedonic model. Instrumenting for air pollution greatly increases the magnitude of the estimated coefficient on particulate matter concentration in a regression of housing prices on local amenities. The elasticity of housing prices with respect to air pollution estimated by instrumental variables is -0.50 to -0.63 . Income is essentially unaffected by air pollution. Since housing accounts for approximately one-fifth of a household's total expenditures, and the hedonic approach assumes that the entire value of local amenities is incorporated into housing prices and income, this estimate corresponds to an elasticity of total willingness to pay of -0.10 to -0.13 .

\footnotetext{
${ }^{2}$ As a likely contrast, consider the case of households sorting across school districts within a single MSA in response to changes in school quality. Here we would expect that migration costs would be low, and that households would be highly motivated, leading to an expectation that the bias may be quite small.
} 
These initial results provide a benchmark for assessing the results of our residential sorting model. In line with intuition, the estimated value of clean air rises considerably when migration costs are taken into account. In our full model, the elasticity of total willingness to pay with respect to air pollution is estimated to be between -0.34 and -0.43 . In dollar terms, these elasticities correspond to marginal willingness to pay between $\$ 149$ and $\$ 185$. By comparison, the marginal willingness to pay estimated from the conventional hedonic model is $\$ 55$. In other words, the value of clean air implied by our residential sorting model is roughly three times greater than that found by applying the standard hedonic approach to the same data. Importantly, we show that our parameter estimates are robust to a range of alternative specifications.

These results suggest that migration costs are large enough (relative to the benefits from air quality) that only a third of the total economic value of the improvements in air quality over the 1990s was reflected in housing prices. These results have important implications for policy, suggesting that the economic benefits of regulations that reduced particulate matter emissions are substantially larger than found in previous studies.

The remainder of the paper proceeds as follows. The next section demonstrates the difficulties that mobility costs pose for the standard wage-hedonic model, and then develops the alternative econometric approach we use in this paper. Section 3 describes the data we use to identify both models. Section 4 details our empirical specification, and Section 5 presents our results. Section 6 concludes.

\section{Econometric models for valuing local amenities}

\subsection{Incorporating mobility costs into the traditional hedonic model}

Consider the following variant of Roback's (1982) model, incorporating mobility costs. We present the simplest possible version of this model in order to demonstrate the basic intuition. At the end of the section, we argue that extending the model to make it more realistic will only exacerbate the difficulties introduced by mobility costs.

As in Roback's model, all individuals simultaneously choose their location along with consumption of a composite commmodity $C$ and a non-traded good ("housing") $H$. Each location $j$ is characterized by a quantity $X_{j}$ of a location-specific amenity ("air quality"). In addition, there is a moving $\operatorname{cost} M_{j}$ associated with settling in city $j$. Following Roback, we assume that individuals have identical preferences and abilities. To keep the model as simple as possible, we suppose that all individuals are born in the same place, and that moving costs are a monotonic function of the amenity level. For example, we might imagine that everyone is born in a central location, and that other cities are arranged in concentric rings with amenities improving as one moves outward. While heroic, these assumptions are useful in conveying the basic intuition; we discuss the consequences of more general assumptions below. 
Each individual chooses her location $j$, along with consumption of $C$ and $H$, to maximize her utility subject to a budget constraint:

$$
\max _{\left\{C, H, X_{j}\right\}} U\left(C, H ; X_{j}, M_{j}\right) \quad \text { s.t. } \quad C+\rho_{j} H=I_{j}
$$

where $I_{j}$ is income in location $j$; $\rho_{j}$ is the price of housing in location $j$; and the price of the composite commodity is normalized to unity. In equilibrium each individual must be indifferent among locations; if not, she would prefer to move. Hence indirect utility, denoted $V$, is constant:

$$
V\left(I_{j}, \rho_{j} ; X_{j}, M_{j}\right) \equiv \bar{V}
$$

The individual's problem is to trade off local amenities against wages and rents (which affect the budget constraint and determine the individual's consumption of commodity $C$ ). Taking the total derivative of equation (2) and using Roy's Identity to substitute for $H=-V_{p} / V_{I}$, we arrive at the following equation for the implicit amenity price $p^{*}$ :

$$
p^{*}=H \frac{d \rho}{d X}-\frac{d I}{d X}-\frac{V_{M}}{V_{I}} \frac{d M}{d X}
$$

Hence $p^{*}$ is the marginal willingness to pay: more precisely, the change in income that would exactly compensate the individual for a marginal change in the amenity at her chosen location. The first two terms on the right-hand side of equation (3) are the familiar terms from Roback's analysis. If mobility is costless $\left(V_{M}=0\right)$, or mobility costs are constant $(d M=0)$, then the model is identical to Roback's. In those cases, the implicit price of the amenity $X$ can be measured as the extra cost of housing minus the compensating wage increase.

When mobility costs are positive and vary with location, the familiar equation no longer holds. Suppose that the amenity increases with distance from 0 . In this case, $V_{M}<0$ (since mobility is costly) and $d M / d X>0$. Thus the true value of a marginal change in the amenity, given by $p^{*}$, is greater than the sum of the housing price and wage effects. Intuitively, when it is more costly to move to locations with better amenities, the housing and labor markets will appear to undervalue those amenities: in order to induce anyone to move to the more attractive locales, rents must be lower (or wages higher) than they would in a world without mobility costs. 
Even this simple model poses difficulties for empirical analysis. If moving costs could be directly observed, then $d M / d X$ could be estimated much as the housing price $(d \rho / d X)$ and income $(d I / d X)$ gradients are, and the implicit price $p^{*}$ could be inferred. But $M$ is likely to be unobservable, since it represents the disutility of moving to an unfamiliar place far from home. Moreover, the restrictive assumptions we have made so far amount to the best case scenario for the traditional model. For example, suppose that individuals are born in different locations. Then the indifference condition (2) need no longer hold for all individuals in all locations, invalidating the total differential approach that determines the key marginal conditions given by equation (3). Or suppose that mobility costs do not vary systematically with location; then there is no longer any reason to expect that the implicit price must be equal across locations, which is the central identifying assumption of the hedonic model. We conclude that when mobility costs are likely to be significant, a different empirical strategy is necessary.

\subsection{A model of residential sorting}

To surmount these difficulties, we develop a structural approach that explicitly models the location decision as taking place prior to the consumption of housing and the composite commodity. Essentially, we push the analysis back a step, examining the utility maximization problem in (1) rather than simply analyzing the equilibrium condition implicit in (3). Estimation proceeds in two steps. First, we specify a discrete-choice model of the household location decision. Doing so allows us to estimate city-specific fixed effects that represent the composite utility of local attributes. Second, we regress these estimated fixed effects on local amenities, using instrumental variables to correct for likely endogeneity.

We start by assuming the following utility function for individual $i$ living in location $j$ and consuming quantities $C_{i}$ and $H_{i}$ of the numeraire good and housing, respectively:

$$
U_{i, j}=C_{i}^{\beta_{C}} H_{i}^{\beta_{H}} X_{j}^{\beta_{X}} e^{M_{i, j}+\xi_{j}+\eta_{i, j}}
$$

As before, $X_{j}$ denotes the local amenity of interest (here, air quality). $M_{i, j}$ measures the long-run (dis)utility of migration associated with moving from $i$ 's birth location to destination $j$. This formulation is meant to capture mobility constraints, broadly defined. Unobservable attributes of location $j$ are captured in $\xi_{j}$. Finally, $\eta_{i, j}$ represents an individual-specific idiosyncratic component of utility that is assumed independent of mobility costs and city characteristics.

Individuals maximize their utility subject to the budget constraint in equation (1). Incorporating that budget constraint into the utility function, differentiating with respect to $H_{i}$, and rearranging yields: 


$$
H_{i, j}^{*}=\frac{\beta_{H}}{\beta_{H}+\beta_{C}} \frac{I_{i, j}}{\rho_{j}}
$$

Equation (5) states that housing expenditure accounts for a constant fraction of income, given by $\beta_{H} /\left(\beta_{H}+\right.$ $\beta_{C}$ ). For the sake of exposition, we assume that $\rho_{j}$ (the price of housing services in location $j$ ) is known; in the empirical analysis we will estimate it from the data, as described in Section 4 below.

Substituting for $H^{*}$ in (4) and using the budget constraint yields the indirect utility function:

$$
V_{i, j}=I_{i, j}^{\beta_{I}} e^{M_{i, j}-\beta_{H} \ln \rho_{j}+\beta_{X} \ln X_{j}+\xi_{j}+\eta_{i, j}}
$$

where $\beta_{I} \equiv \beta_{C}+\beta_{H}$. Marginal willingness to pay (MWTP) for the amenity $X_{j}$ equals the marginal rate of substitution between $X_{j}$ and income: i.e., for individual $i, M W T P_{i}=\frac{\beta_{X}}{\beta_{I}} \frac{I_{i, j}^{*}}{X_{j}}$. Note that while the coefficient on the amenity, $\beta_{X}$, is constant across individuals, MWTP varies with income.

The analysis so far assumes that income $I_{i, j}$ is known for every individual in every region. In practice, of course, we must estimate what income would have been in regions not chosen. Thus we decompose income into a predicted mean and an idiosyncratic error term: i.e., $I_{i, j}=\hat{I}_{i, j}+\varepsilon^{I}{ }_{i, j}$. (In Section 4, we describe how we estimate income from the data.) Substituting this into equation (6) and taking logs yields:

$$
\ln V_{i, j}=\beta_{I} \ln \hat{I}_{i, j}+M_{i, j}+\theta_{j}+v_{i, j}
$$

where

$$
\theta_{j}=-\beta_{H} \ln \rho_{j}+\beta_{X} \ln X_{j}+\xi_{j}
$$

and

$$
v_{i, j} \equiv \beta_{I} \varepsilon_{i, j}^{I}+\eta_{i, j}
$$


$\theta_{j}$ comprises all of the utility-relevant attributes of location $j$ that are constant across individuals. Meanwhile, $v_{i, j}$ is an error term that summarizes individual $i$ 's idiosyncratic preferences for location $j$.

Each individual chooses her location to maximize her utility. We assume that the idiosyncratic city preferences, i.e., the $\left\{v_{i, j}\right\}$, are independently and identically distributed as type I extreme value. This implies that the share of the population choosing to live in city $j$ is given by a logit specification. In practice, it is convenient to divide the right-hand side of equation (7) by $\beta_{I}$, the marginal utility of income. Let tildes denote variables multiplied by $1 / \beta_{I}$, e.g., $\tilde{\theta}=\theta / \beta_{I}$. Hence the probability that individual $I$ settles in location $j$ can be written

$$
P\left(\ln \tilde{V}_{i, j} \geq \ln \tilde{V}_{i, l} \forall l \neq j\right)=\frac{e^{\sigma\left(\ln \hat{I}_{i, j}+\tilde{M}_{i, j}+\tilde{\theta}_{j}\right)}}{\sum_{q=1}^{J} e^{\sigma\left(\ln \hat{I}_{i, q}+\tilde{M}_{i, q}+\tilde{\theta}_{q}\right)}} .
$$

The parameter $\sigma \equiv 1 / \beta_{I}$ is a logit scaling parameter. We estimate equation (10) by maximum likelihood.

We recover the $\{\tilde{\theta}\}$ as parameters in the logit estimation. These city-specific fixed effects represent the indirect utility (somewhat loosely, the "quality of life") from residing in each city, independent of mobility costs or income. In the second stage of estimation, we regress the estimated $\{\tilde{\theta}\}$ on local air pollution concentrations and other local amenities. From equation (8), we have

$$
\tilde{\theta}_{j}=-\tilde{\beta}_{H} \ln \rho_{j}+\tilde{\beta}_{X} \ln X_{j}+\tilde{\xi}_{j}
$$

Notice that $\widetilde{\beta}_{X}=M W T P_{i} \times\left(\frac{X_{j}}{I_{i, j}^{*}}\right)$. Thus the coefficient on $\ln X_{j}$ in equation (11) provides an estimate of the negative of the elasticity of willingness to pay with respect to air quality.

\subsection{Relationship between the two approaches}

The discrete-choice model just outlined is closely related to the Roback model. In the latter setting, all individuals are identical (i.e., $\eta_{i, j} \equiv 0$ ) and indifferent among locations, hence $V$ is constant. Taking the total derivative of equation (6) and setting it equal to zero yields (after some algebra and treating $\xi_{j}$ like another element of $X_{j}$ with a coefficient equal to 1 ): 


$$
\frac{1}{V} \frac{d V}{d X}=\frac{\beta_{I}}{I} \frac{d I}{d X}+\frac{d M}{d X}+\frac{\beta_{X}}{X}-\beta_{H} \frac{d \ln \rho}{d X}=0
$$

$$
\Rightarrow p^{*}=\frac{\beta_{X}}{\beta_{I}} I=H^{*} \frac{d \rho}{d X}-\frac{d I}{d X}-\frac{V_{M}}{V_{I}} \frac{d M}{d X}
$$

which is identical to equation (3). Nonetheless, the identifying assumptions of the two models are very different. The Roback model uses individuals' indifference among locations to derive the result in equation (13). Since in that model individuals equate their marginal rate of substitution with the implicit amenity price, estimating the elements of (13) amounts to inferring the marginal willingness to pay.

In contrast, our discrete-choice model relies on location decisions to reveal preferences about local amenities. In our model, individuals sort among locations on the basis of idiosyncratic tastes, and thus have strict preferences over location. If we are willing to assume that a city's appeal is a weighted sum of the city's characteristics, and that the weights are constant among individuals, then we can identify the underlying marginal willingness to pay directly from an equation such as (11). These additional assumptions represent the cost of our approach. The benefit is that it readily allows us to incorporate mobility costs. As we showed above, the presence of mobility costs complicates inference in the traditional hedonic model. In the empirical analysis that follows, we confirm that allowing for mobility costs makes a large difference in the estimated value of clean air.

Our discrete-choice model also highlights the question of how the size of a city should be used in inferring the value of local amenities. City size plays only an indirect role (i.e., through equilibrium housing prices and incomes) in the conventional wage-hedonic model. In contrast, our approach - by relying on residential location to reveal preferences - infers higher utility for places chosen by a larger

share of individuals. All else equal, bigger cities must have larger estimated values of $\tilde{\theta}_{j}$. If big cities are big because of the observable amenities they offer, then the larger estimated city fixed effects convey useful information about how people value local attributes. On the other hand, city size might enter into individuals' utility directly (e.g., positively through agglomeration effects or negatively via congestion costs). If city size is also correlated with local amenities (e.g., larger cities have more manufacturing facilities and thus poorer air quality), then omitting it will introduce bias. Accordingly, in our empirical analysis we report results from specifications with and without population included as a covariate.

\subsection{Identification}

Two final econometric issues must be addressed in estimating equation the second stage of our model, given by equation (11). First, the price of housing services, $\rho_{j}$, varies with observable characteristics of 
city $j$, and is likely correlated with unobserved local characteristics in $\xi_{j}$. We solve this (minor) problem by moving $\tilde{\beta}_{H} \ln \rho_{j}$ to the left-hand side of the regression equation. Note that $\tilde{\beta}_{H}=\frac{\rho_{j} H_{i}^{*}}{I_{i, j}^{*}}$, the share of income devoted to housing. We set this parameter equal to its median value in our sample, which is $0.2 .^{3}$

Second, amenity levels are likely correlated with local unobservable attributes. In our case of air quality, local economic activity is likely to be positively correlated with local air pollution as well as local rents and wages. As a consequence, naïve estimation of equation (11) by OLS is likely to yield biased parameter estimates. To address this potential source of bias, previous research has attempted to isolate a component of air pollution that is orthogonal to economic activity. In a recent paper, for example, Chay and Greenstone (2005) use discontinuities implicit in the Clean Air Act to isolate a source of pseudorandom variation in regulatory intensity across similar locations.

Following Chay and Greenstone, we combine two strategies to deal with this potential correlation. First, we estimate equation (11) in first differences, using panel data from 1990 and 2000:

$$
\Delta \tilde{\theta}_{j}+\tilde{\beta}_{H} \Delta \ln \rho_{j}=\tilde{\beta}_{X} \Delta X{ }_{j}+\tilde{\zeta}_{j}
$$

where, for example, $\Delta \tilde{\theta}_{j} \equiv \tilde{\theta}_{2000}-\tilde{\theta}_{1990}$; and $\tilde{\zeta}_{j}$ is the time varying component of the unobservable $\tilde{\xi}_{j}$. Note that we have moved $\tilde{\beta}_{H} \Delta \ln \rho_{j}$ to the left-hand side of the regression equation. Taking first differences eliminates any bias due to correlation between persistent air pollution and permanent unobserved city characteristics - for example, a concentration of highly polluting manufacturing industries, or perennial traffic congestion. However, one might still worry about potential correlation between $\tilde{\zeta}_{j}$ and $\Delta X_{j}{ }^{4}$. Hence we also need to find an instrument for air pollution.

We develop a novel instrument that exploits the geography of particulate matter formation and transmission. Pollution travels long distances: particulates emitted from Midwestern power plants, for example, contribute substantially to air pollution in the Northeast and Mid-Atlantic. At the same time, such emissions are likely to be uncorrelated with housing prices or local economic activity. Drawing on this intuition, we instrument for changes in local air pollution using changes in particulate matter

\footnotetext{
${ }^{3}$ The estimate of 0.2 corresponds to the share of income spent on housing in our sample of individuals in the microcensus data, using a 30-year fixed mortgage rate of 9\%, which is the average of the values in 1990 and 2000. In our empirical analysis, we show that our results are robust to other choices of this parameter.

${ }^{4}$ Suppose, for example, that $\widetilde{\zeta}_{j}$ includes the effects of an economic recession in location $j$. If reduced economic activity is correlated with reductions in PM pollution from reduced economic activity, the estimate of $\tilde{\beta}_{X}$ may be biased upward
} 
originating from distant sources. In particular, for the years 1990 and 1999, we compute the particulate matter in location $j$ that is attributable to all sources located at least 80 kilometers from that location, and use the difference between the two measures as our instrument for the change in air pollution. We describe the construction of the instrument in detail in Section 3. The key step is the use of a county-tocounty source-receptor (S-R) matrix developed for the U.S. Environmental Protection Agency. This matrix relates emissions from nearly 6,000 sources throughout the U.S. to pollution concentrations in the 3,080 receptor counties. By excluding sources within a chosen radius, we can construct a measure of the pollution concentration for a given city that is attributable to distant sources.

Figure 1 illustrates our instrumenting strategy. The figure depicts the computed contributions of emissions from counties more than 80 kilometers away to local air quality in the Raleigh-Durham (NC) MSA. Darker shading represents source counties with greater contributions to the ambient concentration of particulate matter. Because the prevailing winds in the United States blow from west to east, the greatest sources of pollution are counties to the west of Raleigh-Durham. As might be expected, two urban counties in North Carolina contribute the most pollution: Mecklenburg County to the southwest (whose seat is the city of Charlotte) and Forsyth County to the west (Winston-Salem). However, the third most significant contributor to ambient particulate matter concentrations in the Raleigh area is nearly 800 $\mathrm{km}$ away in western Tennessee: the enormous coal-fired Johnsonville power plant operated by the Tennessee Valley Authority.

\section{Data}

\subsection{Primary data sources}

The data used for this analysis come from several sources, all publicly available. For the discrete choice model of residential location decisions, as well as the regressions used to estimate individual income and the price of housing services at the MSA level, we draw on the one and five percent micro data samples of the 1990 and 2000 U.S. Population Censuses, respectively. The census data describe attributes of the household head along with the household's composition. The data set we use for our analysis consists of random samples of 10,000 household heads in each year who are under the age of 35 and reside in one of 242 metropolitan statistical areas. We treat the household head as the decision-maker, and focus on his/her attributes, along with those of the dwelling in which the household resides. Migration variables are calculated from data describing the household's state of birth and the location of each MSA. We exclude household heads over 35 years old to ensure that location decisions are driven by current local attributes. The 242 MSAs that comprise our choice set include the larger U.S. cities, and contains approximately 86 percent of the total U.S. metropolitan population in both 1990 and 2000. Appendix Table A1 describes the key census variables used in the analysis. 
To estimate willingness to pay for air quality, we require data on pollution, local economic activity, and a range of local amenities. We describe the construction of our air pollution measures and instruments in detail below. Information on income, population, and employment comes from the Regional Economic Information System database maintained by the Bureau of Economic Analysis. Data on other local amenities are taken from various editions of the County and City Data Book and the Places Rated Almanac (Savageau and Boyer 1993; Savageau and D’Agostino 2000). ${ }^{5}$ Table 2 presents summary statistics and a full description of the variables used in the analysis.

\subsection{Air quality measures}

Our measure of air pollution is the ambient concentration of particulate matter. ${ }^{6}$ Particulate matter refers to airborne small particles, fine solids, and aerosols that form as a result of activities as diverse as the fossil fuel combustion, mining, agriculture, construction and demolition, and driving on unpaved roads. While most of the particles resulting from these processes are relatively large in size (i.e., approximately $1 / 7^{\text {th }}$ the diameter of a human hair), smaller particles result from chemical processes that occur when sulfur dioxide, nitrogen oxides, and volatile organics react with other compounds in the atmosphere. The result is an array of pollutants, collectively known as "PM10" (because they are all smaller than 10 micrometers in size), that carry with them serious health consequences. ${ }^{7}$

${ }^{5}$ Data from the REIS and CCDB are at the county level. We aggregate up to the metro-area level using the same MSA definitions as we use in the pollution data (based on MSA designations in 1990). Doing so ensures that our definitions of MSAs remain constant in both years, even as the official Census designations changed.

${ }^{6} \mathrm{In}$ an ideal world, we would estimate our model on other measures of ambient air pollution as well, such as sulfur dioxide $\left(\mathrm{SO}_{2}\right)$ or ground-level ozone $\left(\mathrm{O}_{3}\right)$. However, we are unaware of any fine-grained source-receptor matrix for other pollutants comparable to the PM10 S-R matrix we use here. This prevents us from implementing our instrumental variables strategy for other pollutants; our empirical results confirm the importance of doing so. A consolation is that PM10 is far and away the most important air pollutant in terms of human health effects. Moreover, it is the pollutant that has been most commonly studied in the previous literature (albeit under its previous guise of "Total Suspended Particulates," or TSP.) Finally, to the extent that PM10 concentrations are correlated with other important pollutants, our results will apply more broadly. Such correlation is probably more likely for $\mathrm{SO}_{2}$ (which results from similar anthropogenic processes and transported similar distances) than for $\mathrm{O}_{3}$, whose creation depends on poorly understood interactions between manmade $\mathrm{NO}_{\mathrm{x}}$ emissions and biogenic volatile organic compounds.

${ }^{7}$ Beginning with the Harvard Six City Study (Dockery et al., 1993), thousands of analyses have found serious health effects from atmospheric particulate matter. These are most severe for the young and the elderly - especially those suffering from asthma (Lin et al., 2002; Norris et al., 1999; Slaughter et al., 2003; Tolbert et al., 2000). Fine particles have been shown to enter the bloodstream, increasing the risk of heart attacks and strokes (Hong et al., 2002; Tsai et al., 2003; D’Ippoliti et al., 2003). Studies have also found evidence of lung tissue inflammation (Ghio et al., 2000), reduced lung function in children (Gauderman et al., 2002), increased risk of lung cancer (Pope et al., 2002), and even the possibility of heritable diseases (Samet et al., 2004). 
We estimate ambient pollution concentrations for each MSA in 1990 and 1999 using data on emissions of particulates and sulfur dioxide (a precursor to PM10). ${ }^{8}$ The data are taken from the National Emissions Inventory maintained by the EPA. To translate emissions into concentrations of particulate matter, we use the PM10 module of the Source-Receptor (S-R) Matrix Model, described in Latimer (1996) and Abt (2000). ${ }^{9}$ This model, used by EPA and its contractors to estimate the health effects of particulate emissions, draws on an atmospheric model called the Climatological Regional Dispersion Model (CRDM). The great advantage of this S-R matrix is its fine-grained resolution: it is a source-tocounty matrix of transfer coefficients, where cell $(s, r)$ contains the transfer coefficient relating emissions of a particular pollutant in source county $s$ to PM10 concentrations in receptor county $r$. The full matrix for each pollutant includes a transfer coefficients from 5903 sources to 3080 receptor counties. The coefficients account for "area sources" in each of 3080 counties (stationary sources of pollution too small to be individually identified - e.g., construction sites); 565 individually identified major point sources (e.g., tall stacks at electric power plants); and miscellaneous smaller point sources grouped at the county level in 2228 counties (e.g., shorter stacks at manufacturing facilities).

With these matrices in hand, generating estimated PM10 concentrations in each county for each year is simply a matter of matrix algebra. Let $\boldsymbol{S}_{t}{ }^{P M}$ and $\boldsymbol{S}_{t}{ }^{S O 2}$ denote the (1 x 5903) vectors of emissions of particular matter and sulfur dioxide, respectively, from all sources in year $t$; and let $\Gamma^{P M}$ and $\Gamma^{S O 2}$ denote the corresponding S-R matrices. Then the estimated vector of county-level PM10 concentrations in year $t$ is $\boldsymbol{P} \boldsymbol{M}_{t}=\boldsymbol{S}_{t}{ }^{P M} \boldsymbol{\Gamma}^{P M}+\boldsymbol{S}_{t}^{S O 2} \boldsymbol{\Gamma}^{S O 2}$. We calculate the metro-area concentration by averaging across the constituent counties in each MSA. These computed concentrations provide our measures of air pollution in a given location in a given year. They represent average ambient concentrations of particulate matter throughout the year, based on actual emissions and prevailing meteorological patterns. ${ }^{10}$

Figures 2 and 3 illustrate our pollution data, depicting computed PM10 concentrations in 1999 for each of the 242 MSAs in our data. Darker shadings correspond to greater concentrations of particulate matter. The western and eastern United States are depicted separately, but the same shading gradient is used. Note that ambient concentrations of particulates generally increase from west to east, mirroring the

\footnotetext{
${ }^{8}$ We use data for 1999 rather than 2000 because the National Emissions Inventory is collected at three-year intervals.

${ }^{9}$ We thank Wayne Gray and his co-authors for generously sharing the S-R matrix with us. The discussion of the matrix is based in part on the discussion in Shadbegian, Gray, and Morgan (2004).

${ }^{10}$ We use the predicted measures for two reasons: first, they do not depend on the placement of particular air monitors or idiosyncratic weather events and wind patters; second, they lend themselves well to our instrumental variables strategy. Importantly, our computed measures of air quality are positively correlated with EPA data based on air quality monitors, with correlations significantly different from zero at $p<0.001$.
} 
underlying weather patterns. Thus the cities of the West Coast have relatively low levels of particulates on the whole, while the nation's highest concentrations occur in Atlanta and New York.

\subsection{Instrumental variables approach}

To create our instruments, only a slight twist is needed. First, we calculate distances from the center of each source county (or the actual location of point sources) to the center of each receptor county. ${ }^{11}$ Given some distance $D$, we then compute $P M_{t}^{D}=S_{t}^{P M} \boldsymbol{\Gamma}_{\mathbf{D}}^{P M}+\boldsymbol{S}_{t}^{S O 2} \boldsymbol{\Gamma}_{\mathbf{D}}{ }^{S O 2}$, where $\boldsymbol{\Gamma}_{\mathbf{D}}{ }^{P M}$ (for example) is the S-R matrix for particulate emissions, with the transfer coefficient in cell $(s, r)$ replaced by a zero if the distance from source $s$ to county $r$ is less than $D$. In the empirical analysis, we use a distance of $D=80 \mathrm{~km}$ (50 miles). Since the regressor is the change in the natural logarithm of PM10 concentrations (i.e., $\Delta \ln \boldsymbol{P M}$ ), we use as the basis for our instrument the corresponding change in the estimated logarithm of the contribution of distant sources, i.e., $\Delta \ln \boldsymbol{P} \boldsymbol{M}^{80} \equiv \ln \left(\boldsymbol{P} \boldsymbol{M}_{1999}^{80}\right)-\ln \left(\boldsymbol{P} \boldsymbol{M}_{1990}^{80}\right)$.

The validity of this approach depends on the orthogonality of distant pollution and local economic activity. One potential concern in this context might be regional variation in how distant U.S. sources affect local air pollution. Because prevailing winds blow from west to east, the contribution of distant sources to local air pollution increases in the same direction. For example, the relative importance of distant sources is likely to be very different in Syracuse than in San Diego. If cities in a given region also experience common economic shocks, our instrument may fail the exclusion restriction. To solve this problem, we take two important steps. First, we condition the full analysis on a set of nine Census regional dummies. Second, in creating our instruments, we interact our estimates of "distant pollution" i.e., the vector $\Delta \ln \boldsymbol{P} \boldsymbol{M}^{80}$ - with dummy variables for the nine census regions used in the analysis. Thus our instrument for $\Delta \boldsymbol{P M}$ is $\Delta \boldsymbol{P} \boldsymbol{M}_{R}^{80} \equiv \Delta \boldsymbol{P} \boldsymbol{M}^{80} \times \mathbf{R}$, where $\mathbf{R}$ is a $J \times 9$ matrix with cell $R(j, r)$ equal to 1 if city $j$ is in region $r$, and zero otherwise. This approach is a conservative one. Having conditioned on region, our model must identify the effects of air pollution entirely off of intra-regional effects. Moreover, as we show in the empirical analysis, our results are robust to using the "unconditional" instrument - that is, the measure of distant air pollution alone, without regional interactions.

Table 3 presents evidence supporting our instrumenting strategy. The table reports correlations between three measures of air pollution and observable characteristics at the metro-area level. We present three measures of pollution: estimated pollution from all sources (i.e., $\boldsymbol{P M}$ ); the estimated contribution to air pollution from sources greater than $50 \mathrm{~km}$ distant (i.e., $\boldsymbol{P} \boldsymbol{M}^{50}$ ); and the estimated contribution from sources greater than $80 \mathrm{~km}$ distant (i.e., $\boldsymbol{P} \boldsymbol{M}^{80}$ ). Note that the first of these is our measure of ambient air

\footnotetext{
${ }^{11}$ For MSAs with multiple counties, we apply the distance exclusion for each source uniformly for all counties within the MSA, based on the distance of the nearest county in the MSA to the particular source.
} 
quality, while the third is the basis of our instrument. We consider correlations between these measures of air quality and local economic activity, as measured by the number of manufacturing establishments, total employment, and total income. We report correlations for the years 1990 and 1999, and for the change between those years. For our instruments, we report correlations with and without conditioning on the census region. Numbers in boldface are significantly different from zero at the $5 \%$ level.

The first column of the table shows correlations between local economic activity and the computed MSA PM10 concentration. Local pollution and local economic activity are strongly and positively correlated in the levels. This confirms the intuition that a naïve regression of housing prices (or city fixed effects) on local air quality is likely to yield biased results. Note that we find a strong but negative correlation in the differences, for total employment and income. This result is driven by falling PM10 concentrations and growing economic activity in four of the largest cities in the U.S. (New York, Los Angeles, Chicago, and Houston).

The cells in the next four columns and the bottom set of rows report correlations between local economic activity and variations on our instrument. As shown in the far right-hand column, our primary instrument (based on pollution from sources more than $80 \mathrm{~km}$ away and conditional on region) is essentially uncorrelated with manufacturing establishments, employment, or income. These near-zero correlations suggests that the portion of PM10 concentration due to sources outside $80 \mathrm{~km}$ is uncorrelated with local economic activity and thus is a reasonable instrument. The correlations are somewhat larger (but still insignificant) for the less restrictive instrument that excludes sources within 50 kilometers.

Table 3 illustrates as well the importance of conditioning the analysis on regional dummies; compare the correlations in columns (4) (without regional controls) and (5) (with regional controls). Of course, the ultimate source of concern is the correlation between our instrument and unobservable characteristics of metropolitan regions. Nonetheless, Table 3 provides as much support for our approach as observable data might be expected to provide.

\section{$4 \quad$ Econometric specification}

Several steps are needed to implement the residential sorting model outlined in Section 2. First, we must estimate housing prices and incomes in each location. Next, we must choose a representation of mobility costs. We can then use a logit model of location choice to estimate the city-specific fixed effects. Finally, we regress those fixed effects on local attributes. We discuss the details of each step in turn. Throughout this analysis, we use $i$ to index households, $j$ to index locations (MSAs), and $t$ to index the year (1990 or 2000). We will often pool data from both years. Note that while the set of metropolitan areas is the same in each year, the set of households is not. 
One approach to housing prices would be to take an aggregate measure of housing prices - for example, the median value of a home in each MSA. However, such an approach raises potentially serious problems of aggregation bias. In particular, home values might rise because of unobserved changes in the quality of the housing stock, rather than changes in local amenities. If these changes in housing supply are correlated with local amenities, an endogeneity problem arises. ${ }^{12}$

We employ a different approach that takes explicit account of the characteristics of individual homes. Let $P_{i, j, t}$ denote the value of the home owned by household $i$ in location $j$ appearing in year $t$, which we define as the value of the house (for owner-occupied housing) or monthly rent (for rental units). We model $P_{i, j, t}$ as a function of the characteristics of the dwelling, given by a vector $\boldsymbol{h}_{i, t}$, and a scaling parameter $\rho_{j, t}$ specific to city $j$ and year $t$ :

$$
P_{i, j, t}=\rho_{j, t} e^{\mathbf{h}_{\mathbf{i}, t} \boldsymbol{\varphi}_{t}+\lambda_{j, t} \Omega_{i, t}+\varepsilon_{i, j, t}^{H}}
$$

$\Omega_{i, t}$ is a dummy variable that equals 1 if household $i$ owns its home and 0 otherwise; thus $\lambda_{j, t}$ measures the premium on owned housing. Taking logs, equation (15) becomes:

$$
\ln P_{i, j, t}=\ln \rho_{j, t}+\lambda_{j, t} \Omega_{i, t}+\mathbf{h}_{\mathbf{i}, t} \boldsymbol{\varphi}_{t}+\varepsilon_{i, j, t}^{H}
$$

Along with housing characteristics, the parameters $\varphi_{\mathrm{t}}$ yield an index of "housing services" each period, defined as $H_{i, t}=\exp \left(\mathbf{h}_{\mathbf{i}, t} \boldsymbol{\varphi}_{t}\right)$. Hence the parameter $\rho_{j, t}$ measures the effective "price of housing services" in a particular location and a particular year. Because we control for the bundle of housing services, these prices provide a consistent measure of the true price of housing across metropolitan areas with different housing stocks. We can readily estimate these prices as the MSA and time specific intercepts in a regression of equation (16), using the census microdata described in Section 3.

Next, consider income. We do not observe the income that a given individual would earn in every location, but only what he earns in his chosen city. In the micro-data used for estimation, however, household heads with similar characteristics are scattered among locations. Hence we can impute the income each individual would earn in every location by estimating a series of location-specific regressions of incomes on a set of individual attributes:

\footnotetext{
${ }^{12}$ Chay and Greenstone (2005) use median home prices at the county level as their dependent variables in hedonic estimation, controlling for the potential bias by including a range of county-level characteristics of the housing market. As they argue, their instrumental variables strategy should also help eliminate the bias.
} 


$$
\begin{aligned}
& \ln I_{i, j, t}=\alpha_{0, j, t}+\alpha_{\text {WHITE }, j, t} \text { WHITE }_{i, t}+\alpha_{M A L E, j, t} \text { MALE }_{i, t}+\alpha_{A G E>60, j, t} A G E>60_{i, t}+ \\
& \alpha_{H S D R O P, j, t} H_{S D R O P}+\alpha_{i, t}+\alpha_{H S G R A D, j, t} H S G R A D_{i, t}+\alpha_{\text {SOMECOLL }, j, t} \operatorname{SOMECOLL~}_{i, t}+ \\
& \alpha_{\text {COLLGRAD }, j, t} \operatorname{COLLGRAD~}_{i, t}+\alpha_{P 1, j, t} P\left(R_{B}, R_{D} \mid E D\right)+\alpha_{P 2, j, t}\left[P\left(R_{B}, R_{D} \mid E D\right)\right]^{2}+\varepsilon_{i, j, t}^{I}
\end{aligned}
$$

The terms $\alpha_{P 1, j, t} P\left(R_{B}, R_{D} \mid E D\right)$ and $\alpha_{P 2, j, t}\left[P\left(R_{B}, R_{D} \mid E D\right)\right]^{2}$ are semi-parametric controls for non-random sorting of individuals across locations, following Dahl (2002). $P\left(R_{B}, R_{D} \mid E D\right)$ is given by:

$$
\begin{array}{r}
P\left(R_{B}, R_{D} \mid E D\right)=H S D R O P_{i} \cdot P\left(R_{B}, R_{D} \mid H S D R O P\right)+H S G R A D_{i} \cdot P\left(R_{B}, R_{D} \mid H S G R A D\right)+ \\
S O M E C O L L_{i} \cdot P\left(R_{B}, R_{D} \mid S O M E C O L L\right)+C O L L G R A D_{i} \cdot P\left(R_{B}, R_{D} \mid C O L L G R A D\right)
\end{array}
$$

and measures the observed percentage of individuals with education level $E D$, born in region $R_{B}$, that are found to be living in region $R_{D}$. This correction therefore requires that our data include individuals of each education type migrating from every region to every region - a condition that is satisfied in the census data for our nine-by-nine regional grid. We estimate the income equation (17) using the census microdata. We use the results to generate predicted income $\hat{I}_{i, j, t} \cdot{ }^{13}$

Next, consider mobility costs. Table 1 suggests that households tend to settle close to where the household head was born. We capture this feature of the data with a flexible migration cost matrix:

$$
\tilde{M}_{i, j, t} \equiv f_{M}\left(\mathbf{d}_{i, j, t} ; \boldsymbol{\mu}\right)=\tilde{\mu}_{S} d_{i, j, t}^{S}+\tilde{\mu}_{R 1} d_{i, j, t}^{R 1}+\tilde{\mu}_{R 2} d_{i, j, t}^{R 2}
$$

where $d_{i, j, t}^{S}=1$ if location $j$ is outside individual $i$ 's birth state ( $=0$ otherwise), $d_{i, j, t}^{R 1}=1$ if location $j$ is outside individual $i$ 's birth region as defined in Table 1 ( $=0$ otherwise), and $d_{i, j, t}^{R 2}=1$ if location $j$ is outside individual $i$ 's macro-region ( $=0$ otherwise). ${ }^{14}$ We normalize migration costs to zero if the household head does not leave his birth state.

We now turn to estimation of the parameter vector $\left\{\tilde{\mu}_{S}, \tilde{\mu}_{R 1}, \tilde{\mu}_{R 2}, \sigma, \tilde{\boldsymbol{\theta}}\right\}$. On the assumption that preferences are stable over time, we can estimate a single set of behavioral parameters (the mobility

\footnotetext{
${ }^{13}$ Note that, in fitting $\hat{I}_{j, k, t}$, one omits the Dahl correction terms described in the next paragraph of the text. These serve only to give the error in equation (15) the needed properties for unbiased OLS estimation.

${ }^{14}$ There are four macro-regions defined by the U. S. Census Bureau: (1) Northeast, (2) Midwest, (3) South, (4) West.
} 
parameters in $\boldsymbol{\mu}$ and the scaling parameter $\sigma$ ) for both years 1990 and 2000. We do this by pooling the data over the two years, and calculating a single likelihood function:

$$
L\left(\tilde{\mu}_{S}, \tilde{\mu}_{R 1}, \tilde{\mu}_{R 2}, \sigma, \tilde{\boldsymbol{\theta}}_{t}\right)=\prod_{t} \prod_{i} \prod_{j=1}^{J}\left[\frac{e^{\sigma\left(\ln \hat{I}_{i, j, t}+\tilde{\mu}_{S} d_{i, j, t}^{S}+\tilde{\mu}_{R 1} d_{i, j, t}^{R 1}+\tilde{\mu}_{R 2} d_{i, j, t}^{R 2}+\tilde{\theta}_{j, t}\right)}}{\sum_{k=1}^{J} e^{\sigma\left(\ln \hat{I}_{i, k, t}+\tilde{\mu}_{S} d_{i, k, t}^{S}+\tilde{\mu}_{R 1} d_{i, k, t}^{R 1}+\tilde{\mu}_{R 2} d_{i, k, t}^{R 2}+\tilde{\theta}_{k, t}\right)}}\right]^{\chi_{i, j . t}}
$$

where $\chi_{i, j, t}$ is an indicator function that equals one if household $i$ observed in year $t$ chooses location $j$, and zero otherwise. ${ }^{15,16}$

Recall that the $\left\{\tilde{\theta}_{j, t}\right\}$ represent composite city-level attributes. Let $P M_{j, t}$ denote the air pollution (PM10) concentration in location $j$ and period $t$, computed as described in Section 3. Note that higher values of $P M_{j, t}$ correspond to worse air quality, so that $\tilde{\beta}_{P M}<0$ if individuals are willing to pay for better air quality. Let $\boldsymbol{Z}_{j, t}$ denote a vector of other observable city attributes. The equation to be estimated in the second stage is thus (updating equation (14))

$$
\Delta \tilde{\theta}_{j}+0.2 \Delta \ln \rho_{j}=\tilde{\beta}_{P M} \Delta \ln P M_{j}+\Delta \boldsymbol{Z}_{j} \tilde{\boldsymbol{\beta}}_{Z}+\tilde{\zeta}_{j}
$$

We estimate equation (21) by instrumental variables, using $\Delta \ln P M_{R, j}^{80}$ as our instrument for $\Delta \ln P M_{j}$. The covariates in $Z_{j, t}$ include a range of local characteristics of metropolitan areas, including local economic activity, crime, local government tax and expenditure data, and rankings of MSAs in various categories of quality of life such as health care provision, arts, and transportation infrastructure.

\section{$5 \quad$ Estimation Results}

\subsection{Housing price and income regressions}

Results from the housing price regressions described in equation (16) are reported in Table A2 for each year. Results are as expected. Bigger, newer houses yield more housing services, as do houses on larger plots and with complete kitchen and plumbing facilities. An inspection of the most and least expensive

\footnotetext{
${ }^{15}$ In practice, when the choice set is large (as it is in our application), estimating the full vector $\tilde{\boldsymbol{\theta}}$ by maximum likelihood can be computationally prohibitive. Berry (1994) provides a computational algorithm whereby these values are imputed indirectly.
} 
cities in the U.S. in terms of the price of housing services corresponds to conventional wisdom. The average price of housing services (in logs) rises from 3.72 in 1990 to 4.48 in 2000, while the premium on owned housing rises from 5.27 to 5.41. All estimates are statistically significant at the usual levels.

Table A3 summarizes the results from the MSA-specific income regressions described in equation (17). Men earn more than women; whites earn more than minorities; and income increases with education. Income falls significantly for those over age 60, reflecting retirement patterns. The premiums for white and male, along with the age penalty, all diminish between 1990 and 2000. In the case of the age penalty, this fall may reflect growing participation in the labor market after age 60. Over the same time period, the premium for college education rises, while that for a high school diploma falls.

\subsection{Estimates from the conventional model}

As a benchmark for comparison with our residential sorting model, we estimate a conventional hedonic model without mobility costs. We estimate the model with and without instruments for air pollution, as a preliminary assessment of the severity of the bias and the success of our instrumenting strategy.

Recall that in the conventional model with costless migration, the implicit price of local amenities - and hence marginal willingness to pay - can be estimated as the sum of the housing price and income gradients with respect to a given amenity. Accordingly, we regress the log of per capita income in MSA $j$ (denoted $Y_{j}$ ) and the price of housing services $\rho_{j}$ (the MSA-specific intercept from the housing price regressions) on particulate matter concentrations $P M_{j}$ and the matrix of regional dummies $\mathbf{R}$. We estimate these equations in first differences:

$$
\begin{gathered}
\ln \Delta Y_{j}=\gamma_{P M, Y} \Delta \ln P M_{j}+\Delta \boldsymbol{Z}_{j} \tilde{\boldsymbol{\beta}}_{Z}+\gamma_{R, Y} R_{j}+u_{j}^{Y} \\
\ln \Delta \rho_{j}=\gamma_{P M, \rho} \Delta \ln P M_{j}+\Delta \boldsymbol{Z}_{j} \tilde{\boldsymbol{\beta}}_{Z}+\gamma_{R, \rho} R_{j}+u_{j}^{\rho}
\end{gathered}
$$

Table 4 reports OLS and IV estimates of the coefficients on PM10 concentrations, i.e., $\gamma_{P M, Y}$ and $\gamma_{P M, \rho} \cdot{ }^{17}$ Both OLS estimates are negative and significantly different from zero. Taken at face value,

\footnotetext{
${ }^{16}$ Note that there is an arbitrary normalization of one of the $\tilde{\theta}_{j, t}$ values: raising the utility of all locations by a constant amount leaves location decisions unchanged. We set $\tilde{\theta}_{j, t}$ equal to zero for the Houston, TX MSA.

${ }^{17}$ For the housing price regression, the covariates in the specifications reported in columns (2) and (4) are the same as in the main results from the residential sorting model (refer to Table 6). For the income regression, the employment rate and number of manufacturing establishments are omitted because they are simultaneously determined with wages and salaries.
} 
these coefficients imply that both housing prices and wages rise when air quality improves. The former effect is consistent with expectations, but not the latter.

The effects of instrumenting for air pollution suggest that the OLS estimates are indeed biased. The estimated elasticity of housing prices with respect to air pollution more than doubles in magnitude, going from -0.30 in the OLS regression to -0.63 in the IV estimates. Meanwhile, the effect of air pollution on per capita income vanishes. We ignore the results from the income equation in computing MWTP. ${ }^{18}$ This is a conservative approach: since the estimates are negative, excluding them inflates the estimates of MWTP from the conventional model. This closes the gap between those estimates and those from our discrete choice model below, leading us to understate the importance of migration costs.

\subsection{Estimates from the residential sorting model}

Table 5 reports parameter estimates from the first-stage residential choice equation (20). Estimates are highly statistically significant and have the expected signs. There is a significant utility cost (-4.31) associated with leaving one's birth state. Costs continue to rise with leaving one's birth region and macro-region, but at a declining rate (i.e., -5.58 and -6.46 , respectively). The estimate of the scaling parameter $\sigma$ is 0.67 . The results of primary interest from the first stage, of course, are the MSA-level fixed effects. These are summarized in Table 2, but can be illustrated by some examples. Controlling for population, the three least attractive metropolitan areas in the year 2000 (those with the most negative values of $\tilde{\theta}_{j}$ ) were New Bedford, MA; Danbury, CT; and Detroit, MI. Cities near the median included Memphis, TN (\#116 out of 242) and Hartford, CT (\#125). Portland, OR and Providence, RI ranked among the top five. ${ }^{19}$

These estimated MSA-level fixed effects are used as the dependent variables in the second-stage estimation of equation (21). Table 6 reports results for a range of specifications. Columns (1) and (2) present OLS estimates; columns (3)-(5) report results from instrumental variables estimation. To account for the potential role played by city size, we include the logarithm of population as a covariate in the specifications reported in columns (2) and (5).

The estimated coefficients on $\Delta \ln (P M)$ are presented in the first row of the table. These coefficients represent the elasticity of willingness to pay (WTP) with respect to air pollution concentrations. As in the housing price regressions (Table 4), OLS yields statistically significant

\footnotetext{
${ }^{18}$ Chay and Greenstone (2005) report a similar finding, and likewise ignore the income estimates in computing MWTP.

${ }^{19}$ In the raw rankings, city size makes a big difference, as we discussed above in Section 2.3. Without controlling for population, the cities with the highest estimates of $\tilde{\theta}_{j, t}$ are Los Angeles, Chicago, and New York. Of course, controlling for population has a much smaller effect on the change from 1990 to 2000.
} 
estimates with the expected sign. Once again, a comparison with the IV results reveals strong evidence of endogeneity bias. When we instrument for air pollution, the estimated elasticity nearly triples in magnitude: the OLS estimates are -0.13 to -0.16 , while the IV estimates range from -0.34 to -0.42 .

Note that these WTP elasticities are not directly comparable to the elasticities of housing prices reported in Table 4. The estimates from the conventional model represent the percent change in housing expenditures associated with a one percent change in air pollution. In contrast, the elasticities estimated by the residential sorting model incorporate not only changes in housing prices, but also foregone income and the disutility from moving. Thus the relative magnitudes of the raw parameter estimates in the conventional model are misleading; in dollar terms, as we shall see below, the results from the residential sorting model are more than three times as large as the results from the conventional approach. Hence including mobility costs matters greatly for our estimates.

For some perspective on what these estimates imply, consider a concrete example. In 1990, the computed PM10 concentration in the New Haven-Meriden MSA was $62.2 \mu \mathrm{g} / \mathrm{m}^{3}$. In the same year, the computed PM10 concentration in the Raleigh-Durham-Chapel Hill MSA was $44.0 \mu \mathrm{g} / \mathrm{m}^{3}$ - roughly $30 \%$ lower than in New Haven, or almost exactly one standard deviation away. (The standard deviation of PM10 in the sample is $18.8 \mathrm{is} \mu \mathrm{g} / \mathrm{m}^{3}$.) The estimated elasticity in the full specification is -0.34 (Table 6 , column 5), implying that the increase in air quality moving from New Haven to Durham would correspond to increase in willingness to pay of 10\%. Per-capita income in 1990 in New Haven was $\$ 23,558$ (in current dollars). Hence the air quality benefits of moving from New Haven to Durham were worth roughly $\$ 2,360$ in foregone consumption.

The estimated coefficients on other local amenities included in the regressions (the covariates in $Z_{j}$ ) vary in significance, but most have the expected signs in the IV estimates. Metropolitan areas with higher government expenditure per capita are significantly more appealing; the fraction of revenue raised by property taxes also has a positive effect. Areas with better health care attract more residents; note that a positive value for $\Delta$ (Health ranking) corresponds to a worsening of health care (and likewise for the arts and transport variables). Culture and transportation are also valued, although the estimates are imprecise. In the specification of column (4), the size of the local economy (as measured by manufacturing establishments) is positively and significantly correlated with the appeal of an area, but the effect vanishes when population is included (the two variables are strongly correlated). Our other measure of local economic activity (i.e., employment as a fraction of the total population) turns out to be insignificant. Importantly, the inclusion of metropolitan area characteristics in general has only a small effect on the estimated coefficient on $\triangle \ln P M$. This robustness provides additional support for our instrumental variables strategy. Finally, the coefficient on population is highly significant, in line with expectations. 
Controlling for population reduces the magnitude of the estimated impact of air quality by just under $20 \%$. Thus the specifications with and without population define the range of willingness to pay.

The coefficients on these covariates allow the computation of elasticities with respect to local amenities other than air quality. For example, the median value of the health care ranking (across both years) is 145.5. Thus the estimated coefficient of -0.001 on $\Delta$ (Health) from the full specification implies that a one percent increase in a city's health care ranking translated into a $0.15 \%$ increase in its attractiveness, as measured by willingness to pay. Similarly, the elasticity of willingness to pay with respect to government spending (at the sample median of 1.34, in thousands of dollars) is 0.23 . By comparison, the WTP elasticity with respect to air quality is larger but of the same general magnitude. Alternatively, we can estimate the percentage increase in willingness to pay that resulted from the median change in local amenities in the data. For government expenditures, the median change was 0.22 , corresponding to a 4\% increase in WTP. The median change in PM concentration was a reduction of 5.7 $\mu \mathrm{g} / \mathrm{m}^{3}-$ which translates into a $5 \%$ increase in WTP. Thus the median improvement in air quality was comparable, in quality-of-life terms, to the median increase in per-capita government expenditure.

Table 7 presents estimated WTP elasticities from a range of other empirical specifications. Panels $(b)$ and $(c)$ represent variation in the dependent variable: in particular, they assume a higher or lower share of expenditures devoted to housing. The results change very little. The parameter estimates are also robust to the precise design of the instrument. The results are very close to the base case when we employ the unconditional instrument (i.e., $\Delta \ln P M^{80}$, without regional interactions; see panel $(d)$ ). The parameter estimates are slightly smaller when we use a less restrictive exclusion distance of 50 kilometers in constructing the instrument (i.e., $\Delta \ln P M^{50}$; see panel $(e)$ ). Indeed, this is exactly as we should expect, since the smaller exclusion distance renders the instrument and the regressor more alike.

Finally, consider the choice of functional form. In the bottom panel of the table, we report results when the change in PM10 concentration enters linearly (rather than in logs). The main effect is to amplify the importance of the covariates. Without controlling for MSA characteristics and other amenities, the estimated elasticity is close to that in the corresponding base specification. With covariates included, however, the log-linear specification yields a much higher estimated elasticity. This is presumably explained by the greater weight that the log-linear specification gives to outliers - in particular, to a handful of large cities that experienced large drops in computed PM10 concentrations.

Based on the evidence presented in Table 7, we conclude that our base specification is a reasonable one, and that our conclusions are robust to the choice of empirical strategy in the second stage. 


\subsection{Marginal willingness to pay}

In our residential sorting model, $\tilde{\beta}_{P M}$ measures the elasticity of willingness to pay with respect to PM10 concentrations; thus we can recover an estimate of marginal willingness to pay for air quality, in dollar terms, by multiplying $-\widetilde{\beta}_{P M}$ by household income and dividing by the PM10 concentration. To calculate a comparable MWTP for the conventional wage-hedonic model, we must first account for the share of expenditure in housing. Since the wage-hedonic model ignores mobility costs, it assumes that individuals' entire willingness to pay is captured in housing prices and incomes. To translate the estimates of housing price elasticities into willingness to pay, therefore, we must first multiply the coefficients from the conventional hedonic model by the share of income devoted to housing expenditures, or 0.2. Multiplying the resulting elasticity of willingness to pay by income, and dividing by the PM10 concentration, yields estimated MWTP, just as in the residential sorting model. ${ }^{20}$

Table 8 reports the results of these computations, using the median values of household income $(\$ 15,679)$ and PM10 concentration (36.0) in our sample as our measures of income and air pollution, respectively. Thus the reported figures for MWTP represent the median household's willingness to pay for a $1 \mu \mathrm{g} / \mathrm{m}^{3}$ reduction in ambient PM10 concentrations, expressed in constant 1982-1984 dollars. ${ }^{21}$ For reference, we have also included the elasticities estimated from the regressions (expressed in terms of air quality rather than air pollution).

The results provide striking evidence of the importance of accounting for endogeneity and mobility costs. When we instrument for air pollution in the full model, the estimated MWTP more than doubles, increasing from $\$ 69$ to $\$ 149$. Incorporating mobility costs matters even more. The marginal willingness to pay estimated by our residential sorting model is much larger than the comparable estimate from the conventional hedonic model: MWTP increases from $\$ 55$ to $\$ 149$ in comparable specifications (compare columns (3) and (4) of Table 8). We also present MWTP for the IV specifications with other sets of covariates (columns (3) and (4) in Table 6). The estimated elasticity of 0.38 from the specification without MSA covariates implies a MWTP of $\$ 165$. When local attributes other than population are included, estimated MWTP rises to $\$ 185$.

\footnotetext{
${ }^{20}$ An alternative approach, more directly in line with theory (see, e.g., eqn (3)) is to calculate MWTP for the conventional model by multiplying the estimated coefficients in Table 4 by the price of housing divided by PM10 concentration (to recover an estimate of the derivative of housing prices with respect to air pollution) and then multiply by the bundle of housing services, $H^{*}$. Of course, this amounts to essentially the same thing; and when we carry out those calculations, using median values, we get nearly identical estimates of WTP.

${ }^{21}$ Measurement in 1982-1984 dollars facilitates comparison with the numbers reported by Smith and Huang (1995) and Chay and Greenstone (2005).
} 
Thus a broad statement of our results is that we find an estimated MWTP for air quality ranging from $\$ 149$ to $\$ 185$, in constant 1982-1984 dollars, for a household whose head earns the median income of $\$ 15,679$. These estimates are large relative to the previous hedonics literature. Chay and Greenstone (2005), for example, report an elasticity of housing prices with respect to particulate matter concentrations of -0.20 to -0.35 - half as large as our conventional hedonic estimates, and roughly one-sixth the size of the elasticities estimated by our residential sorting model.

The discrepancy is even larger in dollar values. Our model identifies marginal willingness to pay in terms of foregone consumption of housing services and other goods. As a result, our estimates correspond to annual marginal willingness to pay - equivalently, the willingness to pay for a one-unit improvement in air quality that lasts for one year. The comparable estimates in Chay and Greenstone correspond to a marginal willingness to pay of \$22 for a reduction in PM10 concentrations - one-seventh the size of our lower estimate. ${ }^{22}$ Moreover, the estimates by Chay and Greenstone were themselves much larger than the previous literature. Part of the discrepancy between their estimates and our estimates using the conventional hedonic approach can be explained by rising willingness to pay between the 1970s and 1990s due to rising incomes; Smith and Huang (1995) report finding such an effect in their comparative analysis of the previous literature. Moreover, our MWTP estimates likely capture the effects of other pollutants whose concentrations are correlated with PM10.

The internal comparison between our estimates from the wage-hedonic model and the residential sorting model remains striking. Incorporating mobility costs yields estimates of marginal willingness to pay that are more than three times as large as estimates from a conventional model. In other words, assuming that migration is costless would result in understating willingness to pay for air quality by roughly two-thirds.

\section{Conclusions}

This paper argues that mobility constraints hinder the use of conventional wage-hedonic techniques to estimate household willingness to pay for local amenities such as clean air. We develop and implement a discrete-choice model that uses data on residential patterns, along with a flexible model of migration costs, to infer the utility of living in individual metropolitan areas across the U.S. We then estimate the marginal willingness to pay for a reduction in air pollution, as measured by the ambient concentration of particulate matter (PM10), using the contribution of distant sources to local air pollution as an instrument.

\footnotetext{
${ }^{22}$ Like the literature before them, Chay and Greenstone frame their results in terms of total suspended particulates (TSP), which was the preferred measure of particulate pollution prior to 1987. In order to convert our WTP estimates to results in terms of TSP, one should divide our measures by approximately 1.82 .
} 
Our results suggest that the conventional approach (ignoring mobility costs) substantially understates the true willingness to pay for air quality. Our estimates imply that the median household would pay $\$ 149$ to $\$ 185$ for a one-unit reduction in PM10 concentrations, in constant 1982-1984 dollars. These estimates are three times as large as the corresponding estimate of marginal willingness to pay from a conventional hedonic model estimated using the same data. Instrumenting for local air pollution makes a large difference in both models - confirming the findings of Chay and Greenstone (2005).

These findings highlight the potential importance of incorporating mobility constraints into hedonic models. We suspect that the consequences of ignoring mobility costs will be greater, the larger are those costs relative to the benefits at stake. For example, while households value clean air, few are likely to leave behind their hometowns and families purely for the sake of modest reductions in air pollution. More generally, mobility costs are more likely to constrain choices among metropolitan areas, rather than among neighborhoods within a metropolitan area.

The adverse health impacts of air pollution have prompted a wide array of legislative responses at both the state and federal levels over the last thirty years. Evaluated according to simple criteria (i.e., emissions reductions and cost-effectiveness), these policies are generally considered to have been successful. Even so, studies find that over 81 million Americans face unhealthy short-term exposure to PM, while 66 million live with chronically high exposure (American Lung Association, 2004). This is cause for concern, particularly in light of current legislative efforts that would reduce the capacity of the EPA to regulate certain pollution sources (i.e., new power plants). While most of these legislative efforts arise out of concern for the cost of compliance with EPA regulations, little is known about the size of the benefits. This complicates careful evaluation based on efficiency criteria. The present study suggests that the true value of clean air may be substantially greater than has been recognized. 


\section{References}

Abt Associates. 2000. "The Particulate-Related Health Benefits of Reducing Power Plant Emissions," prepared for Clean Air Task Force (October).

American Lung Association. 2004. State of the Air: 2004. American Lung Association. Washington, DC.

Bajari, Patrick and Lanier Benkard. 2001. "Demand Estimation with Heterogeneous Consumers and Unobserved Product Characteristics: A Hedonic Approach.” NBER Technical Working Paper No. 272, July 2001.

Berry S. 1994. "Estimating Discrete Choice Models of Product Differentiation." RAND Journal of Economics. 25: 242-262.

Black, D. and T.J. Kneisner. 2003. "On the Measurement of Job Risk in Hedonic Wage Models." Journal of Risk and Uncertainty. 27:205-20.

Black, S.E. 1999. "Do Better Schools Matter? Parental Valuation of Elementary Education.” Quarterly Journal of Economics. 114:577-99

Chay KY and M Greenstone. 2005. "Does Air Quality Matter? Evidence from the Housing Market." Journal of Political Economy. 113(2):376-424.

Dahl, Gordon (2002). "Mobility and the Return to Education: Testing a Roy Model with Multiple Markets," Econometrica. 70(6): 2367-2420.

D'Ippoliti D, F Forastiere, C Ancona, N Agabity, D Fusco, P Michelozzi, and CA Perucci. 2003. “Air Pollution and Myocardial Infarction in Rome: A Case-Crossover Analysis." Epidemiology. 14: 528535.

Dockery DW, CA Pope, X Xu, JD Spengler, JH Ware, ME Fay, BG Ferris, and FE Speizer. 1993. "An Association Between Air Pollution and Mortality in Six U.S. Cities." New England Journal of Medicine. 329: 1753-1759.

Ekeland, Ivar, James Heckman, and Lars Nesheim. 2004. "Identification and Estimation of Hedonic Models." Journal of Political Economy. 112(1.2):S60-S109.

Gauderman WJ, GF Gilliland, H Vora, E Avol, D Stram, R McConnell, D Thomas, F Lurmann, HG Margolis, EB Rappaport, K Berhane, and JM Peters. 2002. "Association Between Air Pollution and Lung Function Growth in Southern California Children: Results From a Second Cohort." American Journal of Respiratory and Critical Care Medicine. 166: 76-84.

Ghio AJ, C Kim, and RB Devlin. 2000. "Concentrated Ambient Air Particles Induce Mild Pulmonary Inflammation in Healthy Human Volunteers." American Journal of Respiratory and Critical Care Medicine. 162(3 Pt.1): 981-988.

Harrison D and DL Rubinfeld. 1978. "Hedonic Housing Prices and the Demand for Clean Air." Journal of Environmental Economics and Management. 5:81-102. 
Heckman, James, Rosa Matzkin, and Lars Nesheim. 2004. "Nonparametric Estimation of Nonadditive Hedonic Models." Mimeo, University of Chicago.

Hong YC, JT Lee, H Kim, EH Ha, J Schwartz, and DC Christiani. 2002. "Effects of Air Pollutants on Acute Stroke Mortality.” Environmental Health Perspectives. 110: 187-191.

Latimer D. A. 1996. "Particulate Matter Source-Receptor Relationships Between All Point and Area Sources in the United States and PSD Class I Area Receptors," prepared for EPA, Office of Air Quality Planning \& Standards (September).

Lin M, Y Chen, RT Burnett, PJ Villeneuve, and D Kerwski. 2002. "The Influence of Ambient Coarse Particulate Matter on Asthma Hospitalization in Children: Case-Crossover and Time-Series Analyses." Environmental Health Perspectives. 110: 575-581.

Moreira, M.J. 2003. "A Conditional Likelihood Ratio Test for Structural Models." Econometrica. 71(4):1027-48.

Norris G, SN YoungPong, JQ Koenig, TV Larson, L Sheppard, and JW Stout. 1999. "An Association Between Fine Particles and Asthma Emergency Department Visits for Children in Seattle." Environmental Health Perspectives. 107: 489-493.

Pope CA, RT Burnett, MJ Thun, EE Calle, D Krewski, K Ito, and GD Thurston. 2002. "Lung Cancer, Cardiopulmonary Mortality, and Long-Term Exposure to Fine Particulate Air Pollution. JAMA. 287: 9.

Palmquist RB. 1984. "Estimating the Demand for the Characteristics of Housing." Review of Economics and Statistics. 66:394-404.

Roback, J. 1982. “Wages, Rents, and the Quality of Life.” Journal of Political Economy. 90:1257-78.

Rosen, Sherwin, (1974). "Hedonic Prices and Implicit Markets: Product Differentiation in Pure Competition." Journal of Political Economy. 82:34-55.

Ridker RG and JA Henning. 1967. "The Determinants of Residential Property Values with Special Reference to Air Pollution." Review of Economics and Statistics. 49:246-257.

Samet JM, DM DeMarini, and HV Malling. 2004. "Do Airborne Particulates Induce Heritable Mutations?" Science. 304(5673):971-972.

Savageau, David and Richard Boyer. 1993. Places Rated Almanac. MacMillan/Prentice Hall Travel, New York, NY.

Savageau, David and Ralph D’Agostino. 2000. Places Rated Almanac: Millennium Edition. Hungry Minds Inc., New York, NY.

Shadbegian RJ, G Wayne, and C Morgan. 2004. "The 1990 Clean Air Act Amendments: Who Got Cleaner Air - and Who Paid For It?," working paper presented at the NBER Summer Institute; accessed from http://www.clarku.edu/faculty/wgray/publications.html. 
Slaughter JC, T Lumley, L Sheppard, JQ Koenig, and GG Shapiro. 2003. "Effects of Ambient Air Pollution on Symptom Severity and Medication Use in Children with Asthma." Annals of Allergy, Asthma, and Immunology. 91: 346-353.

Smith VK and J Huang. 1995. "Can Markets Value Air Quality? A Meta-Analysis of Hedonic Property Value Models." Journal of Political Economy. 103:209-227.

Tolbert PE, JA Mulholland, DD MacIntosh, F Xu, D Daniels, OJ Devine, BP Carlin, M Klein, J Dorley, AJ Butler, DF Nordenberg, H Franklin, PB Ryan, and MC White. 2000. "Air Quality and Pediatric Emergency Room Visits for Asthma in Atlanta, Georgia." American Journal of Epidemiology. 151: 798-810.

Tsai SS, WB Goggins, HF Chiu, and CY Yang. 2003. "Evidence for an Association Between Air Pollution and Daily Stroke Admissions in Kaohsiung, Taiwan.” Stroke. 34(11): 2612-2616.

U.S. EPA. 2001. National Air Quality and Emissions Trends Report, 1999. EPA 454/R-01-004. Internet Available. http://www.epa.gov/air/aqtrnd99/toc.html.

U.S. General Accounting Office. 1983. Siting of Hazardous Waste Landfills and Their Correlation with Racial and Economic Status of Surrounding Communities. GAO: Washington, DC. 

Table 1 - Regional Mobility Patterns

Percent birth region by residence region as of the year 2000 (U.S. Census data)

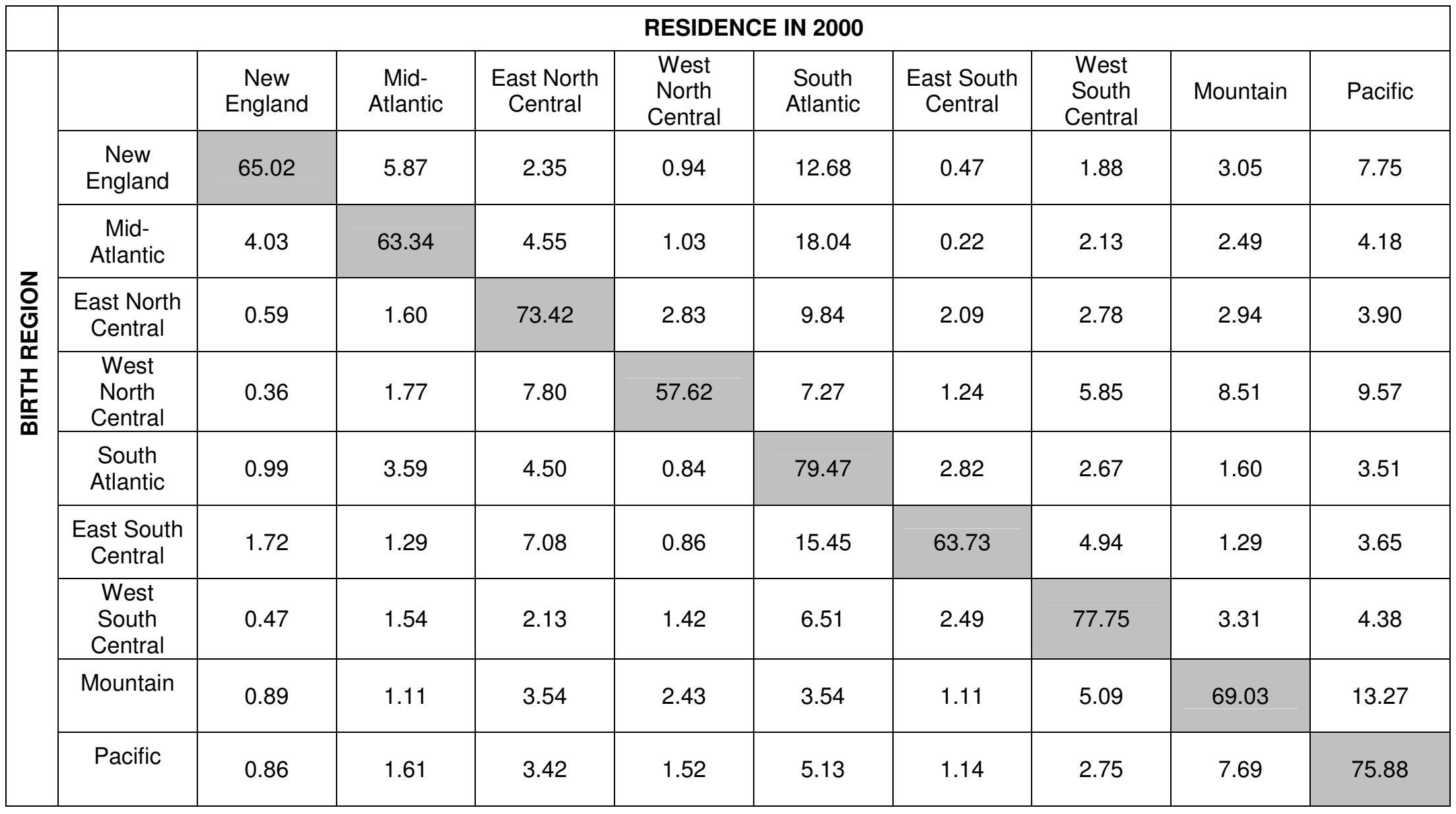

Notes: Rows indicate birth regions; columns denote current residence. For example, the upper-left-hand cell indicates that $65.02 \%$ of household heads born in New England were living in the region during the 2000 Census. Regions are assigned according to Census definitions: Regional Definitions: (1) New England (CT, ME, MA, NH, RI, VT), (2) Middle Atlantic (NJ, NY, PA), (3) East North Central (IL, IN, MI, OH, WI), (4) West North Central (IA, KS, MN, MO,NE, SD, ND), (5) South Atlantic (DE, DC, FL, GA, MD, NC, SC, VA, WV), (6) East South Central (AL, KY, MS, TN), (7) West South Central (AR, LA, OK, TX), (8) Mountain (AZ, CO, ID, MT, NV, NM, UT), and (9) Pacific (AK, CA, HI, OR, WA). 
Table 2: Summary statistics

\begin{tabular}{|c|c|c|c|c|c|c|c|c|}
\hline \multirow[b]{2}{*}{ Variable name Description } & \multicolumn{3}{|c|}{1990} & \multicolumn{2}{|c|}{2000} & \multicolumn{2}{|c|}{ Change } & \multirow[b]{2}{*}{ Source } \\
\hline & & Mean & Std. Dev. & Mean & Std. Dev. & Mean & Std. Dev. & \\
\hline Y Per capita income (\$000s) & & 14.022 & 2.643 & 16.244 & 3.620 & 2.222 & 1.386 & (2) \\
\hline In $\rho \ln$ (Price of housing services) & a & 3.722 & 0.430 & 4.480 & 0.337 & 0.758 & 0.269 & (1) \\
\hline$\tilde{\theta}$ MSA-level fixed effect & a & -0.006 & 1.291 & -0.004 & 1.307 & 0.002 & 0.230 & (1) \\
\hline PM PM10 concentration $(\mu \mathrm{g} / \mathrm{m} 3)$ & & 42.21 & 21.15 & 33.87 & 15.11 & -8.35 & 10.08 & (1) \\
\hline Employment Fraction of population employed & & 0.565 & 0.086 & 0.591 & 0.091 & 0.026 & 0.029 & $(2)$ \\
\hline Manuf. est Number of manufacturing establishments & $b$ & 1078 & 2121 & 1060 & 1878 & -17 & 369 & (3) \\
\hline Crime Crime rate per capita & $c$ & 0.350 & 0.260 & 0.289 & 0.217 & -0.061 & 0.173 & (3) \\
\hline Prop tax Fraction of local tax revenue from property taxes & $d$ & 0.754 & 0.166 & 0.741 & 0.162 & -0.012 & 0.059 & (3) \\
\hline Govt exp Local government expenditure per cap. (\$000) & $d$ & 1.444 & 0.350 & 2.398 & 0.593 & 0.954 & 0.408 & (3) \\
\hline White Fraction of population that is white & & 0.836 & 0.103 & 0.790 & 0.113 & -0.045 & 0.029 & (3) \\
\hline Health Health ranking & & 153.20 & 91.05 & 148.20 & 89.69 & -5.00 & 43.12 & (4) \\
\hline Arts Arts ranking & & 149.71 & 89.32 & 146.35 & 89.84 & -3.37 & 52.77 & (4) \\
\hline Transport Transportation ranking & & 146.31 & 88.42 & 141.43 & 88.44 & -4.88 & 69.75 & (4) \\
\hline Population Population (millions) & & 0.715 & 1.123 & 0.810 & 1.237 & 0.097 & 0.166 & (3) \\
\hline
\end{tabular}

Notes: a: The price of housing services is shown in logs to facilitate comparison with the MSA-level fixed effects.

$b$ : Manufacturing establishments data is for years 1987 and 1997.

c: Crime rate is FBI crime rate in per capita terms, for years 1990 and 1999. d: Property tax and government expenditure data is for 1986-87 and 1996-97.

Sources are (1) estimates from current study, as described in text; (2) Regional Economic Information System (REIS);

(3) County and City Data Books; (4) Places Rated Almanac. All monetary values are expressed in constant 1982-1984 dollars. 
Table 3: Correlations between air quality measures and local characteristics

\begin{tabular}{|c|c|c|c|c|c|c|}
\hline & & \multirow{2}{*}{$\begin{array}{l}\text { MSA PM10 } \\
\text { concentration } \\
\text { Unconditional } \\
\text { (1) }\end{array}$} & \multicolumn{2}{|c|}{$\begin{array}{l}\text { Pollution from } \\
\text { sources }>50 \mathrm{~km}\end{array}$} & \multicolumn{2}{|c|}{$\begin{array}{l}\text { Pollution from } \\
\text { sources }>80 \mathrm{~km}\end{array}$} \\
\hline & & & $\begin{array}{l}\text { Unconditional } \\
\qquad \text { (2) }\end{array}$ & $\begin{array}{l}\text { Conditional on } \\
\text { region } \\
\text { (3) }\end{array}$ & $\begin{array}{l}\text { Unconditional } \\
\qquad \text { (4) }\end{array}$ & $\begin{array}{l}\text { Conditional on } \\
\text { region } \\
\text { (5) }\end{array}$ \\
\hline \multirow{3}{*}{ MSA PM10 concentration } & 1990 & & 0.504 & 0.314 & 0.449 & 0.205 \\
\hline & 1999 & & 0.590 & 0.360 & 0.555 & 0.258 \\
\hline & change & & 0.515 & 0.379 & 0.414 & 0.223 \\
\hline \multirow{3}{*}{ Manufacturing establishments } & 1990 & 0.546 & 0.015 & -0.076 & 0.016 & -0.045 \\
\hline & 1999 & 0.334 & -0.072 & -0.116 & -0.058 & -0.081 \\
\hline & change & 0.592 & 0.222 & 0.044 & 0.244 & 0.058 \\
\hline \multirow{3}{*}{ Employment } & 1990 & 0.577 & -0.014 & -0.067 & -0.009 & -0.035 \\
\hline & 1999 & 0.388 & -0.093 & -0.111 & -0.078 & -0.077 \\
\hline & change & -0.343 & 0.079 & -0.002 & 0.121 & 0.035 \\
\hline \multirow{3}{*}{ Income } & 1990 & 0.586 & 0.014 & -0.053 & 0.006 & -0.035 \\
\hline & 1999 & 0.382 & -0.074 & -0.098 & -0.070 & -0.078 \\
\hline & change & -0.656 & -0.138 & -0.078 & -0.085 & -0.015 \\
\hline
\end{tabular}

Notes: Each cell contains the correlation between the corresponding MSA characteristic (listed in the left-hand column) and the measure of

air quality (listed in the top row). The air quality measures are: predicted concentration of PM10 in the MSA (i.e., the dependent variable in the regressions);

the predicted pollution contributed by sources more than $50 \mathrm{~km}$ distant, both unconditionally and conditional on regional dummies; and

the predicted pollution contributed by sources more than $80 \mathrm{~km}$ distant, again without and with conditioning on region. The latter is the main instrument

used in the analysis.) Boldface denotes correlations that are significantly different from zero at the $5 \%$ level. 
Table 4: Results from conventional wage-hedonic regressions

\begin{tabular}{|c|c|c|c|c|}
\hline \multirow[b]{2}{*}{ Dependent variable } & \multicolumn{2}{|c|}{ OLS } & \multicolumn{2}{|l|}{ IV } \\
\hline & (1) & (2) & (3) & (4) \\
\hline \multirow[t]{2}{*}{$\Delta \ln \rho$} & -0.232 ** & $-0.292^{* * *}$ & $-0.497 * \star \star$ & $-0.634^{* * *}$ \\
\hline & $(0.097)$ & $(0.098)$ & $(0.179)$ & $(0.185)$ \\
\hline \multirow[t]{2}{*}{$\Delta \ln Y$} & $-0.073^{* * *}$ & $-0.074^{* * *}$ & -0.035 & -0.006 \\
\hline & $(0.022)$ & $(0.023)$ & $(0.041)$ & $(0.043)$ \\
\hline MSA covariates & no & yes & no & yes \\
\hline Regional dummies & yes & yes & yes & yes \\
\hline
\end{tabular}

Notes: This table presents results from conventional wage-hedonic regressions. The cells contain the coefficients on $\Delta \mathrm{In}(\mathrm{PM} 10)$, of housing services (first pair of rows) and per capita income (second pair) with respect to increases in air pollution. Columns (1) and (2) present results from OLS regressions; columns (3)-(4) present results using estimated PM10 from sources farther than $80 \mathrm{~km}$ as an instrument. Standard errors are in parentheses; ${ }^{*}$ denotes significance at $10 \%{ }^{* \star}$ at $5 \%$; ${ }^{* \star \star}$ at $1 \%$. 
Table 5 - First Stage Maximum Likelihood Parameter Estimates $\mathrm{N}_{1990}=\mathrm{N}_{2000}=10,000$

\begin{tabular}{|c|c|c|c|}
\hline Variable & Parameter & Coefficient & $t$-statistic \\
\hline \multicolumn{4}{|l|}{ Migration cost } \\
\hline state & $\widetilde{\mu}_{S}$ & -4.31 & -32.69 \\
\hline region & $\tilde{\mu}_{R 1}$ & -1.271 & -17.13 \\
\hline macro-region & $\widetilde{\mu}_{R 2}$ & -0.878 & -18.61 \\
\hline Logit scale parameter & $\sigma$ & 0.673 & 48.36 \\
\hline
\end{tabular}


Table 6: Results from second-stage regressions.

\begin{tabular}{|c|c|c|c|c|c|}
\hline \multirow{2}{*}{$\begin{array}{r}\text { Dependent variable } \\
\Delta \theta+0.25 \Delta \ln (\rho)\end{array}$} & \multicolumn{2}{|c|}{ OLS } & \multicolumn{3}{|c|}{ IV } \\
\hline & $(1)$ & $(2)$ & (3) & (4) & $(5)$ \\
\hline$\Delta / n(P M)$ & $\begin{array}{r}-0.1277 \\
(0.0887)\end{array}$ & $\begin{array}{l}-0.1587^{\star *} \\
(0.0802)\end{array}$ & $\begin{array}{l}-0.3782^{* *} \\
(0.1641)\end{array}$ & $\begin{array}{l}-0.4245^{* * *} \\
(0.1624)\end{array}$ & $\begin{array}{l}-0.3414^{* \star} \\
(0.1498)\end{array}$ \\
\hline$\Delta$ (Crime) & & $\begin{array}{r}0.0149 \\
(0.0992)\end{array}$ & & $\begin{array}{r}0.0115 \\
(0.1091)\end{array}$ & $\begin{array}{r}0.0357 \\
(0.1014)\end{array}$ \\
\hline$\Delta$ (Prop tax $)$ & & $\begin{array}{l}0.5330 * \\
(0.2763)\end{array}$ & & $\begin{array}{l}0.5883 * \\
(0.3013)\end{array}$ & $\begin{array}{l}0.5145^{*} \\
(0.2799)\end{array}$ \\
\hline$\Delta$ (Govt. exp) & & $\begin{array}{l}0.1665^{* \star *} \\
(0.0574)\end{array}$ & & $\begin{array}{l}0.1951^{\star * *} \\
(0.0624)\end{array}$ & $\begin{array}{l}0.1690 * * * \\
(0.0581)\end{array}$ \\
\hline$\Delta$ (White) & & $\begin{array}{r}-0.0955 \\
(0.5780)\end{array}$ & & $\begin{array}{r}-0.1959 \\
(0.6305)\end{array}$ & $\begin{array}{r}-0.0500 \\
(0.5856)\end{array}$ \\
\hline$\Delta($ Health $)$ & & $\begin{array}{l}-0.0009^{* * *} \\
(0.0004)\end{array}$ & & $\begin{array}{l}-0.0010^{\star * *} \\
(0.0004)\end{array}$ & $\begin{array}{l}-0.0010^{\star * \star *} \\
(0.0004)\end{array}$ \\
\hline$\Delta$ (Arts) & & $\begin{array}{r}-0.0001 \\
(0.0003)\end{array}$ & & $\begin{array}{r}-0.0003 \\
(0.0003)\end{array}$ & $\begin{array}{r}-0.0001 \\
(0.0003)\end{array}$ \\
\hline$\Delta($ Transport $)$ & & $\begin{array}{r}-0.0001 \\
(0.0002)\end{array}$ & & $\begin{array}{r}-0.0002 \\
(0.0002)\end{array}$ & $\begin{array}{r}-0.0002 \\
(0.0002)\end{array}$ \\
\hline$\Delta$ (Employment) & & $\begin{array}{r}-0.5452 \\
(0.5809)\end{array}$ & & $\begin{array}{r}-0.9092 \\
(0.6293)\end{array}$ & $\begin{array}{r}-0.4735 \\
(0.5898)\end{array}$ \\
\hline$\Delta / n$ (Manuf. est.) & & $\begin{array}{r}0.0345 \\
(0.1289)\end{array}$ & & $\begin{array}{l}0.4030^{\star \star \star *} \\
(0.1204)\end{array}$ & $\begin{array}{r}0.0297 \\
(0.1304)\end{array}$ \\
\hline$\Delta / n$ (Population) & & $\begin{array}{l}1.2182^{\star * \star} \\
(0.2171)\end{array}$ & & & $\begin{array}{l}1.2223^{* * *} \\
(0.2196)\end{array}$ \\
\hline Constant & $\begin{array}{r}-0.0301 \\
(0.0742)\end{array}$ & $\begin{array}{r}-0.0854 \\
(0.0790)\end{array}$ & $\begin{array}{r}-0.1297 \\
(0.0931)\end{array}$ & $\begin{array}{r}-0.0722 \\
(0.0963)\end{array}$ & $\begin{array}{r}-0.1496 \\
(0.0914)\end{array}$ \\
\hline Regional dummies & yes & yes & yes & yes & yes \\
\hline $\begin{array}{r}\text { R-squared } \\
\text { Observations }\end{array}$ & $\begin{array}{r}0.08 \\
242\end{array}$ & $\begin{array}{r}0.32 \\
242\end{array}$ & $\begin{array}{r}0.05 \\
242\end{array}$ & $\begin{array}{r}0.19 \\
242\end{array}$ & $\begin{array}{r}0.31 \\
242\end{array}$ \\
\hline
\end{tabular}

Notes: Standard errors in parentheses. Asterisks denote significance at * $10 \%$ level; ${ }^{* \star} 5 \%$ level; ${ }^{\star \star *} 1 \%$ level. 
Table 7: Robustness

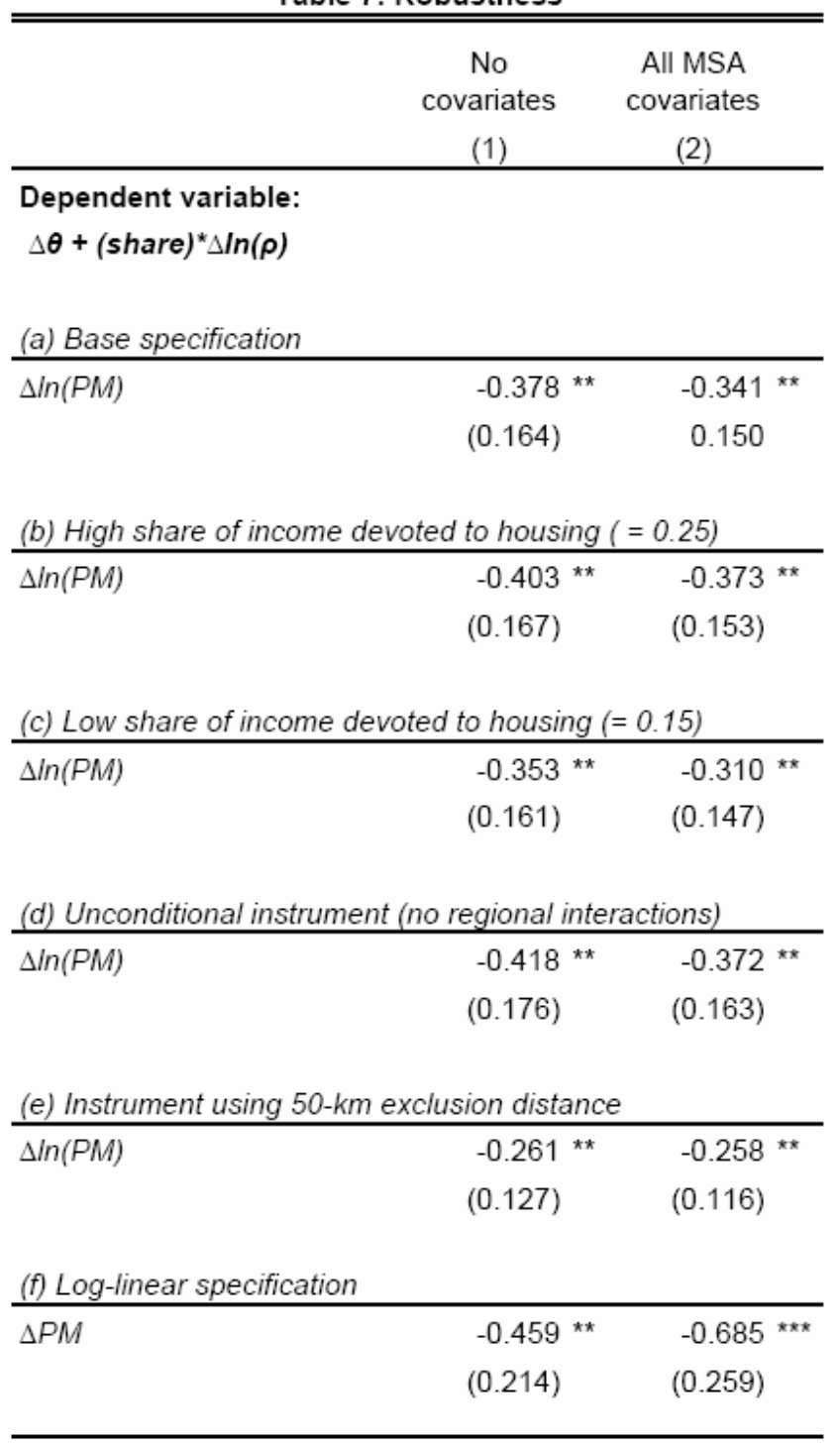

Notes: This table presents estimated coefficients on measures of air quality under a range of specifications The columns correspond to specifications with and without MSA covariates (including population).

The top panel reproduces results from the main specification presented in Table 6 . The second and third panels show results using high (0.25) and low (0.15) values of housing expenditure as a share of income; the base case is 0.2 . Panel (d) the instrument is simply the predicted pollution from sources farther than $80 \mathrm{~km}$, without regional interactions. Panel (e) reports results when the instruments are pollution from sources farther than $50 \mathrm{~km}$ (rather than $80 \mathrm{~km}$ ), interacted with region. The bottom panel uses the same instruments as in the base specification, but measures air pollution (and the corresponding instruments) in levels rather than logs. In the log-linear specification, the estimated coefficients represent income shares; the elasticities presented in the table are those coefficients multiplied by the median value of PM10 in the dataset ( $36.0 \mu \mathrm{g} / \mathrm{m} 3)$. Standard errors are in parentheses; asterisks denote significance at the * $10 \%$ level; ${ }^{\star *} 5 \%$ level; and ${ }^{\star * *} 1 \%$ level. 
Table 8: Estimated marginal willingness to pay for air quality

\begin{tabular}{|c|c|c|c|c|c|c|}
\hline \multirow[b]{3}{*}{ Measure } & \multicolumn{2}{|c|}{ Hedonics } & \multicolumn{4}{|c|}{ Residential sorting } \\
\hline & OLS & IV & OLS & & IV & \\
\hline & $\begin{array}{c}\begin{array}{c}\text { Full } \\
\text { specification( } \\
\text { 1) }\end{array} \\
\end{array}$ & $\begin{array}{c}\text { Full } \\
\text { specification( } \\
\text { 2) } \\
\end{array}$ & $\begin{array}{c}\text { Full } \\
\text { specification( } \\
3 \text { ) } \\
\end{array}$ & $\begin{array}{c}\text { Full } \\
\text { specification( } \\
4) \\
\end{array}$ & $\begin{array}{c}\text { No covariates } \\
(5)\end{array}$ & $\begin{array}{c}\text { No control for } \\
\text { population } \\
(6)\end{array}$ \\
\hline WTP elasticity & 0.06 & 0.13 & 0.16 & 0.34 & 0.38 & 0.42 \\
\hline MWTP & $\$ 25.40$ & $\$ 55.20$ & $\$ 69.10$ & $\$ 148.70$ & $\$ 164.72$ & $\$ 184.89$ \\
\hline
\end{tabular}

Notes: "Hedonics" coefficients are taken from the wage-hedonic model summarized in Table 4 (columns 2 and 4).

"Residential sorting" coefficients are from Table 6; columns 3-6 above correspond to columns 2, 5, 3, and 4 in Table 6, respectively. Marginal willingness-to-pay (MWTP) is calculated by multiplying the regression coefficients by the median household income in constant 1982-84 dollars $(\$ 15,679)$ and dividing by the median PM10 concentration in the sample $(36.0 \mu \mathrm{g} / \mathrm{m} 3)$.

Figures for the wage-hedonic model exclude the estimated effects of PM10 on income,

which were insignificant in the IV model. All estimates are in constant 1982-1984 dollars. 
Figure 1

Contribution to PM10 Concentration in Raleigh-Durham MSA From Sources at Least $80 \mathrm{~km}$ Away

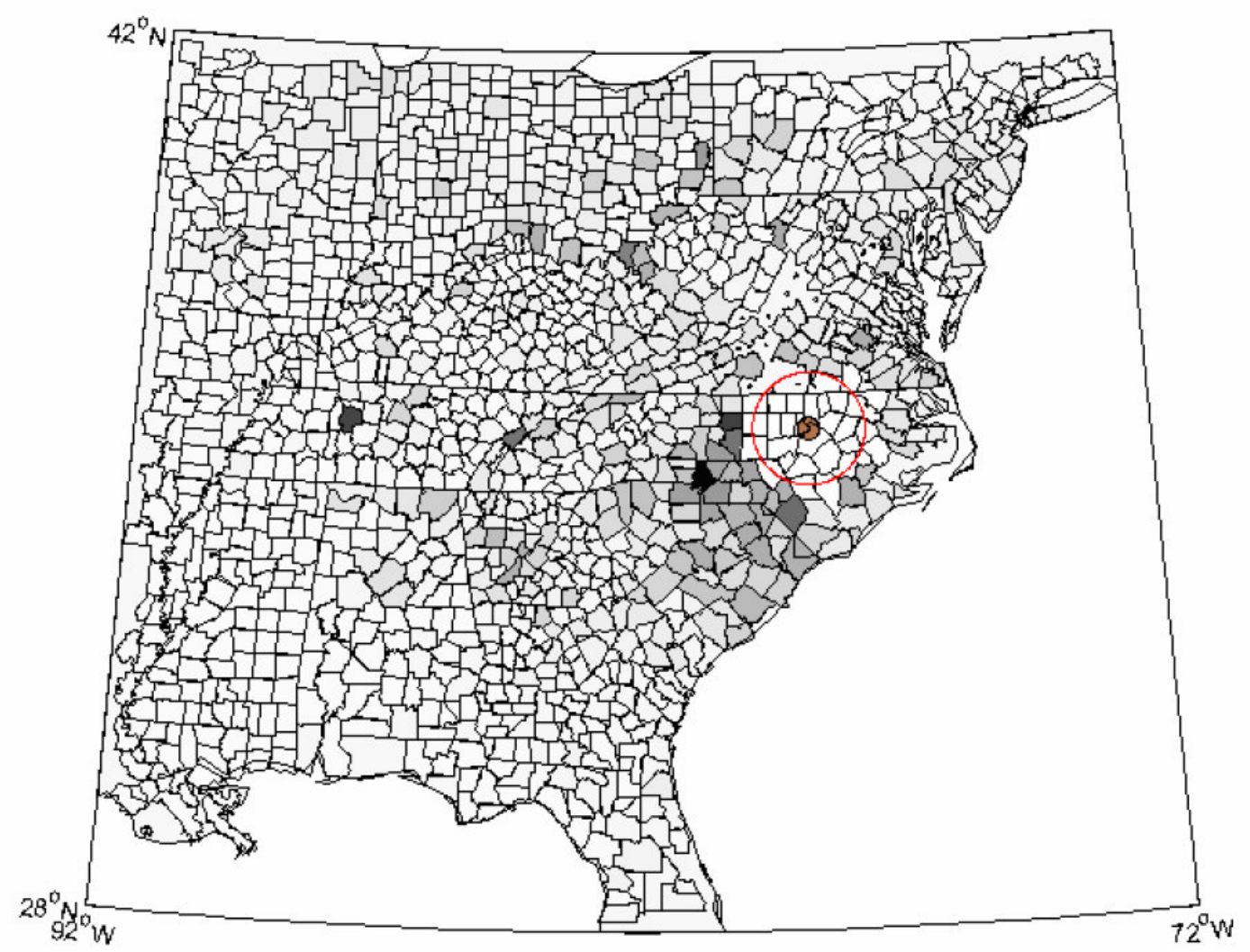


Figure 2

Computed PM10 Concentrations in the Eastern United States ${ }^{23}$

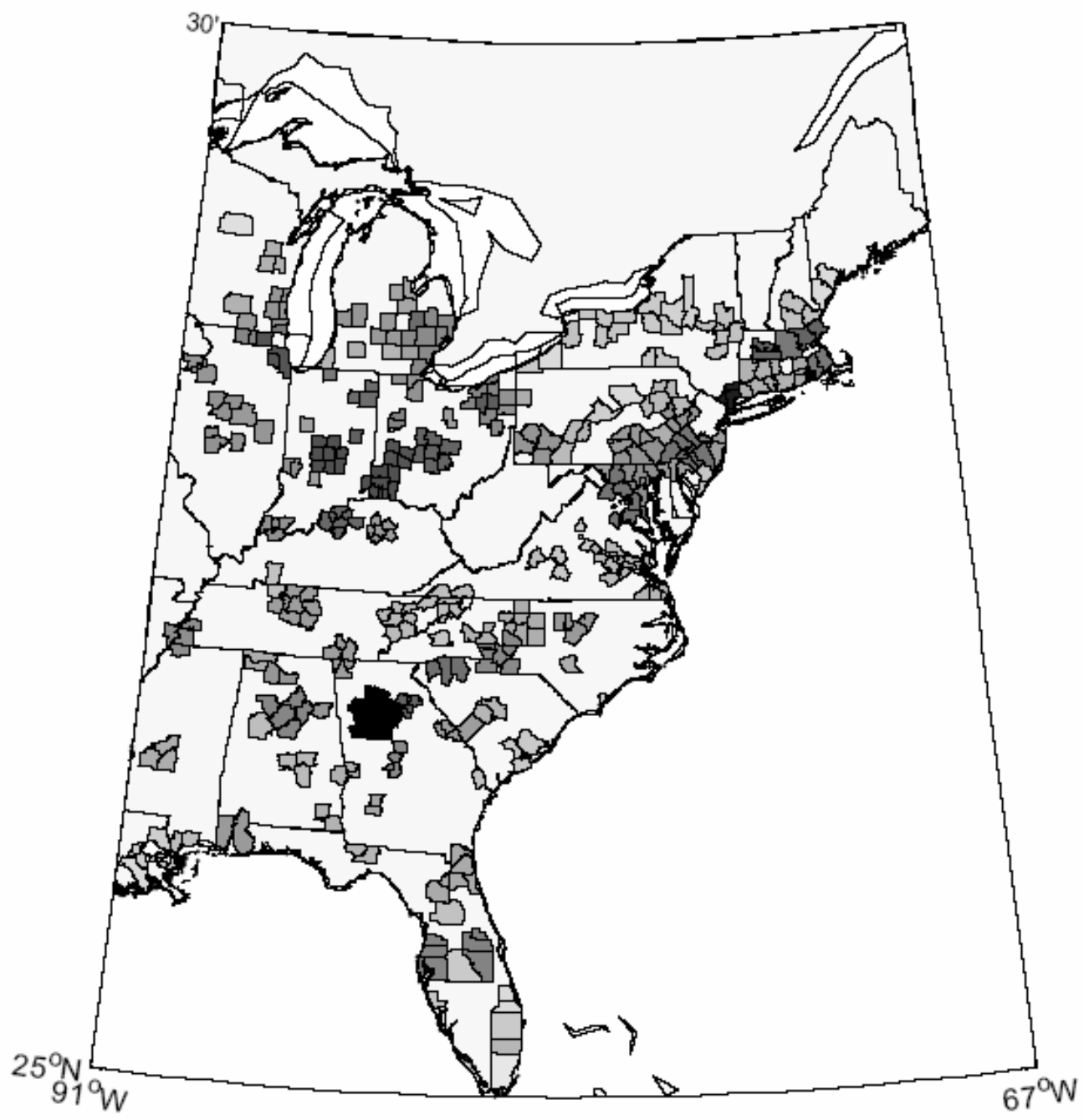

\footnotetext{
${ }^{23} \mathrm{PM} 10$ concentrations are computed with actual emissions data and county-to-county source-receptor matrix.
} 
Figure 3

Computed PM10 Concentrations in the Western United States ${ }^{24}$

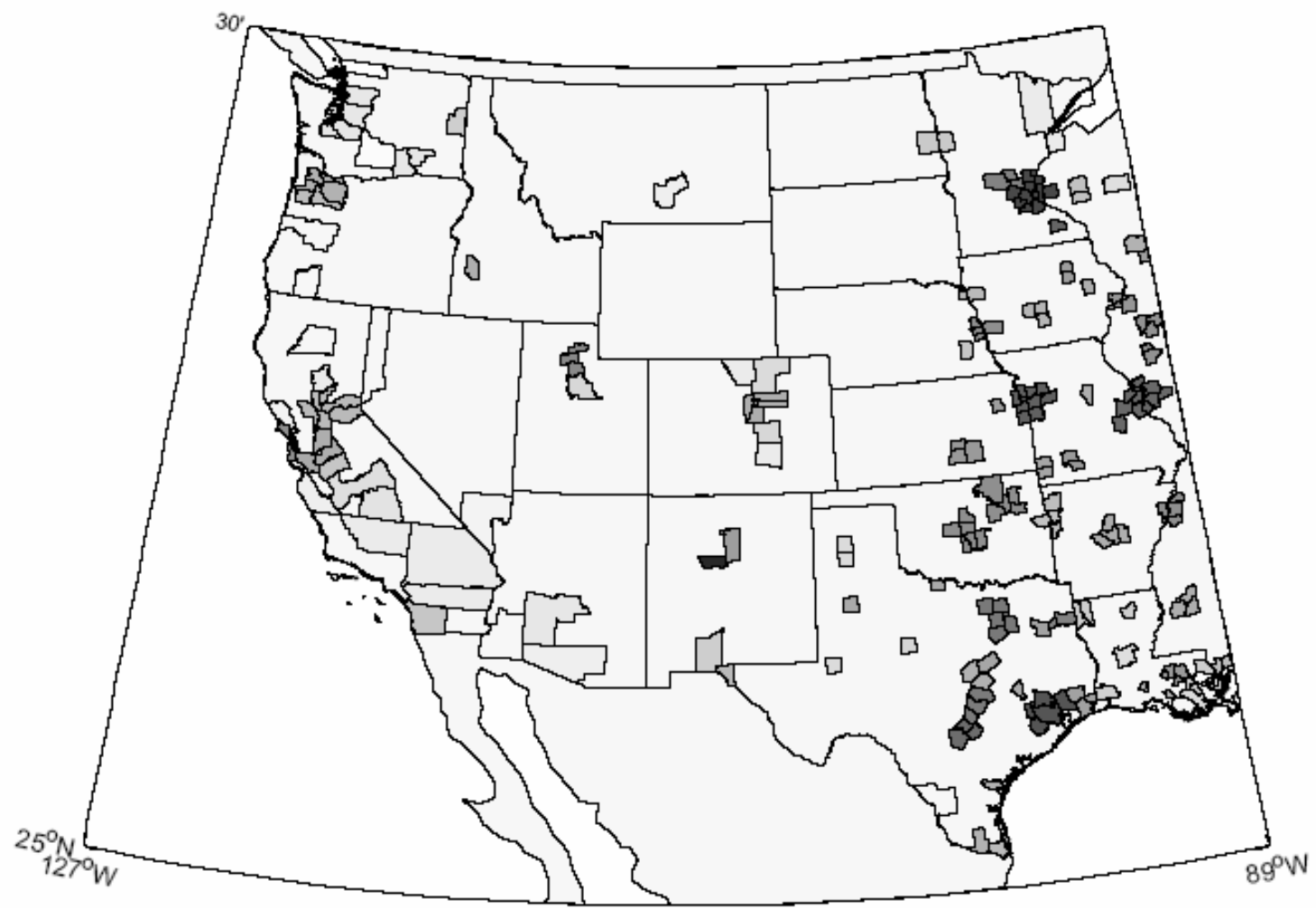

${ }^{24} \mathrm{PM} 10$ concentrations are computed with actual emissions data and county-to-county source-receptor matrix. 


\section{Appendix}

Table A1 - Data Summary

\begin{tabular}{|c|c|c|}
\hline Variable & Mean & Description \\
\hline HSDROP & 0.175 & High school dropout \\
\hline HS & 0.249 & High school graduate \\
\hline SOMECOLL & 0.291 & Completed some college (not four year degree) \\
\hline COLL & 0.286 & College graduate \\
\hline WHITE & 0.770 & Race $=$ White \\
\hline BLACK & 0.125 & Race $=$ Black \\
\hline ASIAN & 0.038 & Race $=$ Asian (Chinese, Japanese, other Asian or Pacific Islander) \\
\hline OTHER & 0.063 & American Indian and other racial categories \\
\hline AGE & 49.36 & Age of the household head \\
\hline MALE & 0.651 & Sex of the household head $(1=$ MALE, $0=$ FEMALE $)$ \\
\hline INCTOT & 42305 & Total income from employment \\
\hline ROOM2 & 0.047 & 2 rooms in dwelling \\
\hline ROOM3 & 0.096 & 3 rooms in dwelling \\
\hline ROOM4 & 0.148 & 4 rooms in dwelling \\
\hline ROOM5 & 0.192 & 5 rooms in dwelling \\
\hline ROOM6 & 0.194 & 6 rooms in dwelling \\
\hline ROOM7 & 0.128 & 7 rooms in dwelling \\
\hline ROOM8 & 0.088 & 8 rooms in dwelling \\
\hline ROOM9 & 0.086 & $9+$ rooms in dwelling \\
\hline BED2 & 0.130 & 1 bedroom dwelling \\
\hline BED3 & 0.268 & 2 bedroom dwelling \\
\hline BED4 & 0.385 & 3 bedroom dwelling \\
\hline BED5 & 0.151 & 4 bedroom dwelling \\
\hline BED6 & 0.035 & $5+$ bedroom dwelling \\
\hline YR1 & 0.018 & $0-1$ year-old dwelling \\
\hline YR2 & 0.070 & 2-5 year-old dwelling \\
\hline YR3 & 0.070 & 6-10 year-old dwelling \\
\hline YR4 & 0.157 & 11-20 year-old dwelling \\
\hline YR5 & 0.176 & 21-30 year-old dwelling \\
\hline YR6 & 0.147 & $31-40$ year-old dwelling \\
\hline YR7 & 0.138 & $41-50$ year-old dwelling \\
\hline UNITS2 & 0.001 & Boat, tent, van, other \\
\hline UNITS3 & 0.590 & 1 family house, detached \\
\hline UNITS4 & 0.066 & 1 family house, attached \\
\hline UNITS5 & 0.046 & 2 family building \\
\hline UNITS6 & 0.048 & 3-4 family building \\
\hline UNITS7 & 0.045 & 5-9 family building \\
\hline UNITS8 & 0.043 & 10-19 family building \\
\hline UNITS9 & 0.035 & 20-49 family building \\
\hline UNITS10 & 0.058 & $50+$ family building \\
\hline ACRE1_9 & 0.104 & Acreage of property 1-9 acres \\
\hline ACRE10 & 0.024 & Acreage of property $10+$ acres \\
\hline NOKITCH & 0.007 & Dwelling does not contain complete kitchen facilities \\
\hline NOPLUMB & 0.005 & Dwelling does not contain complete plumbing facilities \\
\hline OWNER & 0.661 & Dwelling owned \\
\hline RENTER & 0.339 & Dwelling Rented \\
\hline MSA_ID & & Metropolitan Statistical Area identification number \\
\hline BLP & & Birth state \\
\hline
\end{tabular}


Table A2 - Housing Services Index Parameters

\begin{tabular}{|c|c|c|c|c|}
\hline & \multicolumn{2}{|c|}{$1990(\mathrm{~N}=638159)$} & \multicolumn{2}{|c|}{$2000(\mathrm{~N}=3674433)$} \\
\hline & Estimate & t-statistic & Estimate & t-statistic \\
\hline CONSTANT & 4.035 & 477.04 & 4.982 & 1504.54 \\
\hline ROOM2 & 0.033 & 2.50 & 0.096 & 19.17 \\
\hline ROOM3 & 0.058 & 4.04 & 0.115 & 22.18 \\
\hline ROOM4 & 0.123 & 8.32 & 0.126 & 23.28 \\
\hline ROOM5 & 0.217 & 14.51 & 0.208 & 37.57 \\
\hline ROOM6 & 0.362 & 23.85 & 0.347 & 61.66 \\
\hline ROOM7 & 0.524 & 34.16 & 0.495 & 86.81 \\
\hline ROOM8 & 0.665 & 42.73 & 0.634 & 109.32 \\
\hline ROOM9 & 0.857 & 54.55 & 0.855 & 145.26 \\
\hline BED2 & 0.056 & 4.54 & 0.029 & 6.56 \\
\hline BED3 & 0.124 & 9.41 & 0.107 & 22.67 \\
\hline BED4 & 0.135 & 10.01 & 0.155 & 31.90 \\
\hline BED5 & 0.162 & 11.68 & 0.221 & 43.95 \\
\hline BED6 & 0.168 & 11.42 & 0.281 & 51.12 \\
\hline YR1 & 0.534 & 79.52 & 0.479 & 161.47 \\
\hline YR2 & 0.514 & 139.19 & 0.428 & 238.24 \\
\hline YR3 & 0.384 & 104.74 & 0.363 & 206.21 \\
\hline YR4 & 0.287 & 97.37 & 0.250 & 179.26 \\
\hline YR5 & 0.209 & 69.61 & 0.129 & 97.76 \\
\hline YR6 & 0.138 & 45.88 & 0.092 & 67.54 \\
\hline YR7 & 0.056 & 15.93 & 0.064 & 47.10 \\
\hline UNITS2 & 1.018 & 103.35 & -0.449 & -34.18 \\
\hline UNITS3 & 1.154 & 261.36 & 0.748 & 460.14 \\
\hline UNITS4 & 1.027 & 186.73 & 0.628 & 281.46 \\
\hline UNITS5 & 1.283 & 217.15 & 0.873 & 344.37 \\
\hline UNITS6 & 1.310 & 220.37 & 0.891 & 356.72 \\
\hline UNITS7 & 1.297 & 217.80 & 0.886 & 351.96 \\
\hline UNITS8 & 1.347 & 224.03 & 0.917 & 348.26 \\
\hline UNITS9 & 1.304 & 204.79 & 0.842 & 302.06 \\
\hline UNITS10 & 1.267 & 203.63 & 0.873 & 351.96 \\
\hline ACRE1_9 & 0.086 & 28.99 & 0.164 & 120.88 \\
\hline ACRE10 & 0.124 & 24.75 & 0.252 & 88.90 \\
\hline NOKITCH & -0.091 & -7.53 & -0.041 & -7.38 \\
\hline NOPLUMB & -0.448 & -36.09 & -0.258 & -44.53 \\
\hline $\mathrm{R}^{2}$ & \multicolumn{2}{|c|}{0.942} & \multicolumn{2}{|c|}{0.926} \\
\hline
\end{tabular}


Table A3 - Summary of Income Regressions

\begin{tabular}{|c|c|c|c|c|}
\hline \multirow{2}{*}{ Variable } & \multicolumn{2}{|c|}{1990} & \multicolumn{2}{c|}{2000} \\
\cline { 2 - 5 } & $\begin{array}{c}\text { Average } \\
\text { Parameter } \\
\text { Estimate }\end{array}$ & $\begin{array}{c}\text { Standard } \\
\text { Deviation of } \\
\text { Estimates }\end{array}$ & $\begin{array}{c}\text { Average } \\
\text { Parameter } \\
\text { Estimate }\end{array}$ & $\begin{array}{c}\text { Standard } \\
\text { Deviation of } \\
\text { Estimates }\end{array}$ \\
\hline Constant & 8.586 & 0.368 & 8.982 & 0.259 \\
\hline MALE & 0.621 & 0.121 & 0.549 & 0.098 \\
\hline AGE $>60$ & -0.072 & 0.142 & -0.039 & 0.149 \\
\hline WHITE & 0.303 & 0.228 & 0.266 & 0.133 \\
\hline HS & 0.368 & 0.120 & 0.352 & 0.114 \\
\hline SOMECOLL & 0.515 & 0.175 & 0.537 & 0.164 \\
\hline COLLGRAD & 0.949 & 0.185 & 1.009 & 0.158 \\
\hline
\end{tabular}

